\title{
Modulation of Renal Function in a Metabolic Syndrome Rat Model by Antioxidants in Hibiscus sabdariffa L.
}

\author{
Félix Leao Rodríguez-Fierros ${ }^{1}$, Verónica Guarner-Lans ${ }^{2} \mathbb{D}$, María Elena Soto ${ }^{3} \mathbb{D}$, Linaloe Manzano-Pech ${ }^{1}$, \\ Eulises Díaz-Díaz ${ }^{4}$, Elizabeth Soria-Castro ${ }^{1}$, María Esther Rubio-Ruiz ${ }^{2} \mathbb{D}$, Francisco Jiménez-Trejo ${ }^{5}$ \\ and Israel Pérez-Torres ${ }^{1, * \mathbb{D}}$
}

check for updates

Citation: Rodríguez-Fierros, F.L.; Guarner-Lans, V.; Soto, M.E.;

Manzano-Pech, L.; Díaz-Díaz, E.; Soria-Castro, E.; Rubio-Ruiz, M.E.; Jiménez-Trejo, F.; Pérez-Torres, I. Modulation of Renal Function in a Metabolic Syndrome Rat Model by Antioxidants in Hibiscus sabdariffa L. Molecules 2021, 26, 2074. https:// doi.org/10.3390/molecules26072074

Academic Editor: Maria Atanassova

Received: 5 March 2021

Accepted: 31 March 2021

Published: 4 April 2021

Publisher's Note: MDPI stays neutral with regard to jurisdictional claims in published maps and institutional affiliations.

Copyright: (c) 2021 by the authors. Licensee MDPI, Basel, Switzerland. This article is an open access article distributed under the terms and conditions of the Creative Commons Attribution (CC BY) license (https:// creativecommons.org/licenses/by/ $4.0 /)$.
1 Department of Cardiovascular Biomedicine, Instituto Nacional de Cardiología "Ignacio Chávez", Juan Badiano 1, Sección XVI, Tlalpan, Mexico City 14080, Mexico; felixleao@hotmail.com (F.L.R.-F.); loe_mana@hotmail.com (L.M.-P.); elizabethsoria824@gmail.com (E.S.-C.)

2 Department of Physiology, Instituto Nacional de Cardiología "Ignacio Chávez", Juan Badiano 1, Sección XVI, Tlalpan, Mexico City 14080, Mexico; gualanv@yahoo.com (V.G.-L.); esther_rubio_ruiz@yahoo.com (M.E.R.-R.)

3 Department of Immunology, Instituto Nacional de Cardiología “Ignacio Chávez", Juan Badiano 1, Sección XVI, Tlalpan, Mexico City 14080, Mexico; mesoto50@hotmail.com

4 Department of Reproductive Biology, Instituto Nacional de Ciencias Médicas y Nutrición Salvador Zubirán, Vasco de Quiroga 15, Sección XVI, Tlalpan, Mexico City 14000, Mexico; eulisesd@yahoo.com

5 Department of Reproductive Biology, Instituto Nacional de Pediatría, Insurgentes Sur No. 3700-C, Coyoacán, Mexico City 04530, Mexico; trejofj@hotmail.com

* Correspondence: pertorisr@yahoo.com.mx or israel.perez@cardiologia.org.mx; Tel.: +52-5573-2911 (ext. 25203); Fax: +52-5573-0926

Abstract: Metabolic syndrome (MS) is the association of three or more pathologies among which obesity, hypertension, insulin resistance, dyslipidemia, and diabetes are included. It causes oxidative stress (OS) and renal dysfunction. Hibiscus sabdariffa L. (HSL) is a source of natural antioxidants that may control the renal damage caused by the MS. The objective of this work was to evaluate the effect of a $2 \%$ HSL infusion on renal function in a MS rat model induced by the administration of $30 \%$ sucrose in drinking water. 24 male Wistar rats were divided into 3 groups: Control rats, MS rats and MS + HSL. rats. MS rats had increased body weight, systolic blood pressure, triglycerides, insulin, HOMA index, and leptin $(p \leq 0.04)$. Renal function was impaired by an increase in perfusion pressure in the isolated and perfused kidney, albuminuria $(p \leq 0.03)$, and by a decrease in clearance of creatinine $(p \leq 0.04)$. The activity of some antioxidant enzymes including the superoxide dismutase isoforms, peroxidases, glutathione peroxidase, glutathione-S-transferase was decreased $(p \leq 0.05)$. Lipoperoxidation and carbonylation were increased $(p \leq 0.001)$. The nitrates/nitrites ratio, total antioxidant capacity, glutathione levels and vitamin $C$ were decreased $(p \leq 0.03)$. The treatment with $2 \%$ HSL reversed these alterations. The results suggest that the treatment with $2 \%$ HSL infusion protects renal function through its natural antioxidants which favor an improved renal vascular response. The infusion contributes to the increase in the glomerular filtration rate, by promoting an increase in the enzymatic and non-enzymatic antioxidant systems leading to a decrease in OS and reestablishing the normal renal function.

Keywords: metabolic syndrome; Hibiscus sabdariffa L.; oxidative stress; kidney; renal function

\section{Introduction}

Metabolic syndrome (MS) is the association of three or more pathologies including obesity, hypertension, insulin resistance (IR), dyslipidemia and diabetes mellitus that occur simultaneously or sequentially in an individual. It causes alterations to organs and systems and it increases the risk of developing cardiovascular, kidney and liver diseases often leading to premature death [1]. The association between MS and kidney damage is related to obesity, IR, and oxidative stress (OS). In MS, the adipose tissue and the liver release 
pro-inflammatory cytokines and free fatty acids that affect the kidney causing glomerulosclerosis, nephrolithiasis, mesangial cell proliferation and loss of the morphological structure of the nephrons. These molecules also imbalance the response to vasoconstrictor and vasodilator agents in the renal afferent artery thus promoting alterations of the renal blood flow and glomerular ultra-filtration. These changes increase intraglomerular pressure, therefore allowing the passage of high molecular weight molecules such as albumin [2].

On another hand, reactive oxygen species (ROS) are molecules that occur naturally within biological systems and participate in various cellular and immunological activities that benefit the body [3]. However, an excessive increase in their level, caused by different pathologies such as those that comprise MS, leads to OS. This condition alters cellular metabolism through damage to proteins, lipids, enzymes, and DNA [4]. ROS are formed from molecular oxygen in the mitochondria, and through different enzymes such as xanthine oxidase, NADPH oxidase, cytochrome P450 and the inducible nitric oxide synthase (iNOS). The loss of renal function by ROS is due to endothelial dysfunction, damage to the structure of the cells in the glomeruli and renal tubules, inflammation, fibrosis and to genotoxic factors. ROS that participates in renal damage include $\mathrm{O}_{2}{ }^{-}, \mathrm{H}_{2} \mathrm{O}_{2}, \mathrm{ONOO}^{-}$ and $\mathrm{OH}^{-}[5]$.

However, the body possesses enzymatic and non-enzymatic antioxidant systems to eliminate the excess of free radicals. Some of the enzymes that form part of the enzymatic antioxidant system are the superoxide dismutase isoforms (SOD). These enzymes detoxify and protect the cell from the superoxide anion $\left(\mathrm{O}_{2}{ }^{-}\right)$anion by catalyzing the dismutation of two of these free radicals by a metallic cofactor that includes manganese, copper, or zinc. The final product of this reaction is the generation of $\mathrm{H}_{2} \mathrm{O}_{2}$ [6]. $\mathrm{H}_{2} \mathrm{O}_{2}$ is a molecule capable of diffusing through membranes; it has a long half-life and may act as a second messenger in different signaling pathways [7]. It initiates immediate effects such as changes in cell structure, cell proliferation, and recruitment of immune cells. It also damages lipidic membranes and causes necrosis, and apoptosis [8]. However, to detoxify this free radical, the enzymatic antioxidant system is provided with catalase (CAT), peroxidases and glutathione peroxidase (GPx). CAT is a very stable antioxidant enzyme which is not subject to denaturation and proteolysis due to its rigid structure. It has a high activity in the liver and erythrocytes and an average activity in the kidney and adipose tissue [9]. The glutathione peroxidase (GPx) isoform family consists of homologous enzymes that contain a selenocysteine. They are more effective than CAT in the removal of intracellular peroxides under many physiological conditions, and can reduce lipid hydrogen peroxides, and decrease lipid peroxidation (LPO) [10]. Another group of molecules that interact with $\mathrm{H}_{2} \mathrm{O}_{2}$ are peroxidases. They have an iron atom in the ferric form $\left(\mathrm{Fe}^{3+}\right.$ or $\left.\mathrm{Fe}^{\mathrm{III}}\right)$. Peroxidases play an important role in innate immunity and in many physiologically important processes such as apoptosis, inflammation and cell signaling. The activity of peroxidases is decreased in MS [11].

Another enzyme that participates in the detoxification process is glutathione-S-transferase (GST). This enzyme belongs to a superfamily of isoenzymes that include the (alpha $[\alpha], \mathrm{mu}$ $[\mu]$, pi $[\pi]$, omega $[\omega]$, theta $[\theta]$, delta $[\delta]$, zeta $[\varsigma]$, sigma $[\sigma]$, kappa $[\kappa]$ and the mitochondrial $[\mathrm{m}]$ forms. They are multifunctional and are found in the cytoplasm, mitochondria, endoplasmic reticulum, nucleus, cell membrane and in plasma. They function as protective enzymes for endogenous and exogenous cellular detoxification and they neutralize ROS [12]. This detoxification is carried out mainly through enzymatic conjugation with glutathione (GSH) to convert ROS into more soluble compounds that are more easily eliminated [13]. GSH is widely distributed in the cytoplasm and it reacts with ROS. It may also be oxidized by GPx and GST to form glutathione disulfide (GSSG) [14]. After participating in antioxidant functions, it is again reduced by the glutathione reductase (GR) [15].

Furthermore, plants are a source of natural antioxidants. They may function as alternative treatments to control the oxidative damage caused by MS in the kidney. In 
this sense, Hibiscus sabdariffa L. (HSL), also known as Jamaica flower, is a medicinal plant widely used in traditional medicine in Asia, Africa, and America. It contains polyphenols, anthocyanins, protocatechuic acid, epigallocatechins, resveratrol, and flavonoids, which protect against the different pathologies that comprise MS [16]. The effects of different fractions of the HSL infusion at the renal level have been reported in various studies. As an example, polyphenols obtained from HSL improve water exchange and reduce kidney damage in rats with diabetes induced by streptozotocin [17]. Another study showed that $2 \%$ HSL treatment decreased the infiltration of inflammatory cells, the level of NF- $\mathrm{kB}$, and the expression of the genes of the enzymes involved in the production of prostaglandins in BALB/mice with kidney damage caused by LPS, [18]. Therefore, the aim of this work was to evaluate the effect of a $2 \%$ HSL infusion on renal function in a MS rat model induced by the administration of $30 \%$ sucrose in drinking water and evaluating the components of the antioxidant system in of kidney homogenate.

\section{Results}

MS rats showed significant increases in body weight $(p \leq 0.04)$, intra-abdominal fat, systolic blood pressure (SBP), triglycerides (TG), insulin, HOMA index, and leptin vs. the control rats $(p=0.001)$. The treatment with HSL in MS rats, significantly decreased the weight gain, SBP, TG levels, insulin, the marker of resistance to insulin (HOMA index) and leptin $(p \leq 0.04)$ in comparison with the MS rats. The glucose and cholesterol (CT) values did not show significant differences in any of the groups, (Table 1).

Table 1. General characteristic of experimental groups.

\begin{tabular}{cccc}
\hline Variables & Control & MS & MS + HSL. \\
\hline Glucose $(\mathrm{mmol} / \mathrm{L})$ & $114.7 \pm 6.8$ & $113.5 \pm 5.0$ & $118.5 \pm 4.9$ \\
\hline Insulin $(\mu \mathrm{U} / \mathrm{mL})$ & $5.3 \pm 0.5$ & $17.6 \pm 1.2^{* *}$ & $11.6 \pm 1.1^{*}$ \\
\hline HOMA index & $2.0 \pm 0.1$ & $9.9 \pm 1.8^{* *}$ & $4.2 \pm 0.3^{*}$ \\
\hline Triglycerides $(\mathrm{mg} / \mathrm{dL})$ & $52.5 \pm 4.6$ & $139.5 \pm 25.6^{* *}$ & $74.1 \pm 5.9^{*}$ \\
\hline Cholesterol $(\mathrm{mg} / \mathrm{dL})$ & $46.1 \pm 2.1$ & $51.5 \pm 1.7$ & $51.2 \pm 0.8$ \\
\hline Intra-abdominal fat $(\mathrm{g})$ & $3.1 \pm 0.3$ & $11.6 \pm 1.3^{* *}$ & $6.1 \pm 0.4^{*}$ \\
\hline Systolic blood pressure $(\mathrm{mmHg})$ & $119.1 \pm 4.9$ & $140.1 \pm 6.9^{* *}$ & $132.2 \pm 4.4^{*}$ \\
\hline Leptin $(\mathrm{ng} / \mathrm{mL})$ & $1.9 \pm 0.5$ & $13.5 \pm 7.8^{* *}$ & $3.6 \pm 0.8^{*}$ \\
\hline Body mass $(\mathrm{g})$ & $397.8 \pm 26.6$ & $556.8 \pm 14.1^{*}$ & $425.0 \pm 27.6^{*}$
\end{tabular}

Data are mean \pm SE, $n=8$ each group. Statistically significant at ${ }^{*} p<0.04$ control and MS + HSL. vs. MS; ${ }^{* *} p=0.001$ control vs. MS. Abbreviations: MS = metabolic syndrome; MS + HSL. = metabolic syndrome plus Hibiscus sabdariffa L.

Table 2 describes the renal function markers. The MS rats showed deterioration of the renal function evidenced by a significant increase in serum creatinine ( $\mathrm{SCr}$ ), lower urine creatinine ( $\mathrm{UCr}$ ) and therefore decrease in creatinine clearance (CCr). They also had an increase in albuminuria $(p \leq 0.003)$ when compared with the control group. Furthermore, the MS rats showed an increase in water consumption when compared to the control and MS + HSL. groups ( $p \leq 0.003$ and $p \leq 0.001$ respectively). The HSL treatment in the MS rats resulted in a lower $\mathrm{SCr}$, increase $\mathrm{UCr}$ and therefore an increase in $\mathrm{CCr}$ and a decreased in albuminuria $(p \leq 0.001)$.

The top panel in Figure 1 shows the average area size of the glomerular tang in each of the experimental groups. The densitometrical analysis showed a significant decrease in the size of the glomerulus in the MS rats when compared to the control and the MS + HSL. groups ( $p=0.03, p=0.004$ respectively). Figure $1 \mathrm{~A}-\mathrm{C}$ show representative histological sections of a glomerulus in the control, MS, and MS + HSL. groups, respectively. The glomerular spaces and loops with their fine and delicate membrane are preserved in the control and MS + HSL. groups in comparison with those from MS rats which show retracted glomerular tuft, fibrosis, and an increased urinary space with detritus. 
Table 2. Renal function indicators in the experimental groups.

\begin{tabular}{cccc}
\hline Variables & Control & MS & MS + HSL. \\
\hline Drinking wáter $(\mathrm{mL} / 24 \mathrm{~h})$ & $18.12 \pm 2.30$ & $58.75 \pm 5.06^{* *}$ & $35.00 \pm 5.08^{\S}$ \\
\hline Weight of the right kidney $(\mathrm{g})$ & $1.27 \pm 0.03$ & $1.51 \pm 0.08^{\dagger}$ & $1.30 \pm 0.04^{*}$ \\
\hline Urine $(\mathrm{mL} / 24 \mathrm{~h})$ & $13.62 \pm 2.53$ & $24.00 \pm 4.20^{*}$ & $27.00 \pm 3.33$ \\
\hline $\mathrm{UCr}(\mathrm{mg} / \mathrm{dL})$ & $12.32 \pm 1.29$ & $3.95 \pm 0.36^{* *}$ & $6.76 \pm 1.19$ \\
\hline $\mathrm{SCr}(\mathrm{mg} / \mathrm{dL})$ & $0.41 \pm 0.02$ & $0.67 \pm 0.03^{* *}$ & $0.40 \pm 0.02^{\S}$ \\
\hline $\mathrm{CCr}(\mathrm{mL} / \mathrm{min})$ & $2.51 \pm 0.35$ & $1.45 \pm 0.15^{* *}$ & $2.79 \pm 0.55^{*}$ \\
\hline Albuminuria $(\mathrm{mg} / \mathrm{mL})$ & $32.28 \pm 5.54$ & $74.67 \pm 8.57^{* *}$ & $43.08 \pm 7.54^{\S}$ \\
\hline
\end{tabular}

Data are mean \pm SE, $n=8$ each group. Statistically significant at * $p \leq 0.04 \mathrm{MS}+\mathrm{HSL}$. and control vs. MS, ${ }^{+} p=0.01$ control vs. MS, ${ }^{* *} p \leq 0.003$, control vs. MS and ${ }^{\S} p \leq 0.001$ MS + HSL. vs. MS. Abbreviations: MS = metabolic syndrome; MS + HSL. = metabolic syndrome plus Hibiscus sabdariffa L.
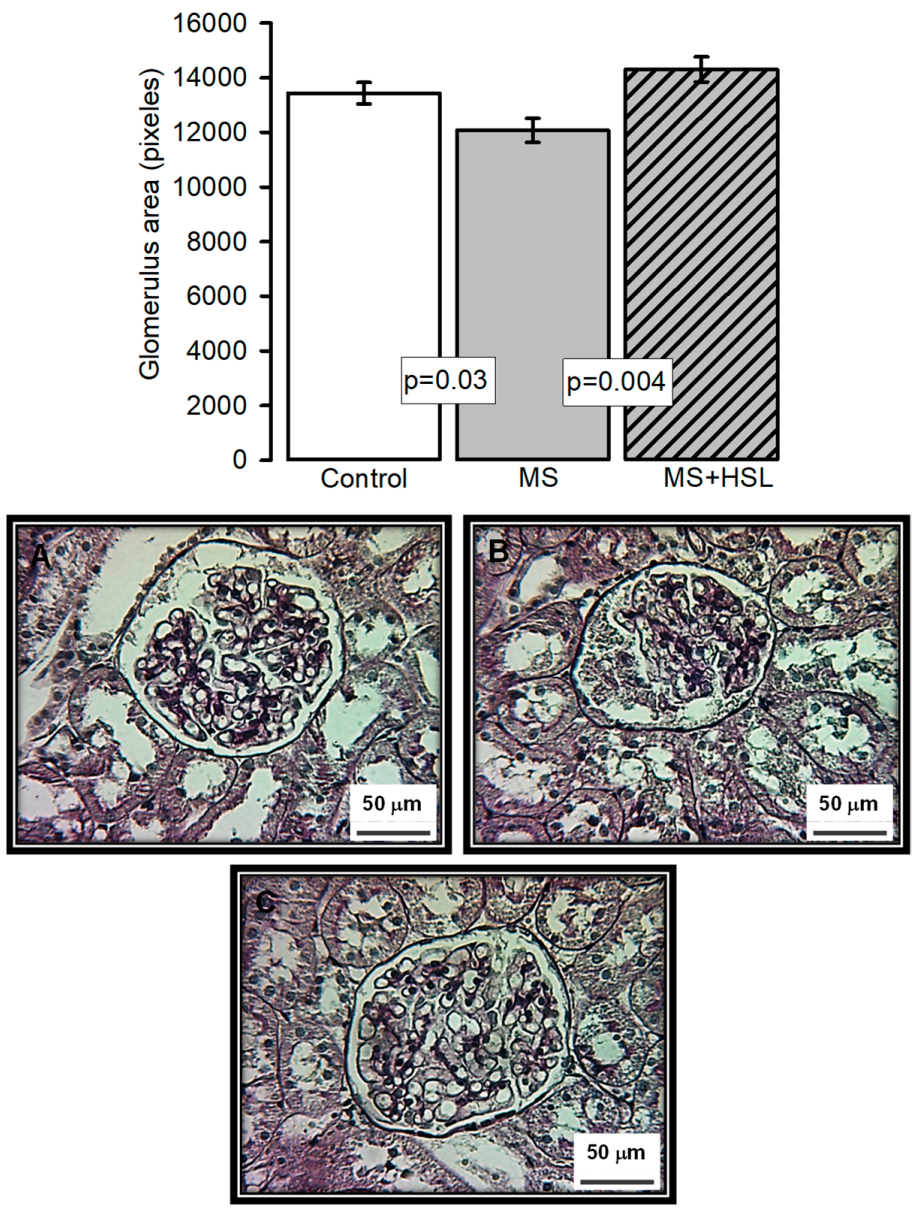

Figure 1. The top panel histogram that represents the densitometric analysis of the glomerular area in the experimental groups. Panel (A-C) Representative Photomicrographs of rat renal cortex. Images show the glomerulus from (A) control rats, (B) MS rats, and (C) MS + HSL. . No abnormalities were observed under light microscopy in control and MS + HSL. groups, where glomerular spaces and loops with their fine and delicate membrane are preserved. However, in the kidney of the MS rats showed retracted glomerular tuft, fibrosis, and an increased urinary space with detritus. (Periodic acid-Schiff stains, $400 \times)$.

Figure 2 shows the changes in the $\Delta$ of PP, which increased significantly $(p=0.02)$ when NE was perfused into the kidney of MS rats in comparison with control rats $(116.8 \pm 49.1 \mathrm{mmHg}$ vs. $45.7 \pm 33.3 \mathrm{mmHg})$. The HSL treatment in MS rats resulted in a significant decrease $(p=0.03)$ in the $\Delta$ of PP when perfused with NE when compared 
to MS rats $(63.2 \pm 20.2 \mathrm{mmHg}$ vs. $116.8 \pm 49.1 \mathrm{mmHg})$. When $\mathrm{NE}$ was perfused in the presence of Ach, the $\Delta$ of PP decreased by $11 \%$ without significant difference in the control rats. The $\Delta$ of PP decreased in the kidney of the MS rats by $26 \%$ when compared to that present only with NE in the same group, with a significant difference $(p=0.01)$. However, when comparing the $\Delta$ of PP between the control and MS groups, a significant increase was observed $(40.6 \pm 22.8 \mathrm{mmHg}$ vs $86.6 \pm 44.4 \mathrm{mmHg}, p=0.01)$. In the MS + HSL. rats, a decrease of $36 \%$ in the $\Delta$ of PP compared to NE in the same group ( $p=0.03$ ) was observed when adding NE in the presence of Ach. In addition, it showed a significant decrease in the $\Delta$ of PP compared to MS rats $(40.4 \pm 22.8 \mathrm{mmHg}$ vs. $86.6 \pm 44.5 \mathrm{mmHg}, p=0.01)$. However, when the NE was perfused in the presence of $\mathrm{H}_{2} \mathrm{O}_{2}$, a decrease in the $\Delta$ of PP of the $52 \%$ was observed in the control group when compared with NE from the same group with a significant difference $(p=0.04)$. However, in the MS group there was a significant decrease in the $\Delta$ of PP of up to $63 \%$ when compared to the vasoconstriction that was present with NE only, in the same group ( $p=0.001)$. When the $\Delta$ of PP between the MS rats and the control rats was analyzed, a significant increase $(43.7 \pm 14.6 \mathrm{mmHg}$ vs. $21.7 \pm 17.2 \mathrm{mmHg}$, $p=0.01)$ was observed. In the MS + HSL. group, there was a $73 \%$ decrease in the $\Delta$ of PP compared with that of the same group $(p=0.001)$, but when compared with the MS rats, a significant decrease in the $\Delta$ of $\mathrm{PP}(17.1 \pm 7.2 \mathrm{mmHg}$ vs. $43.7 \pm 14.6 \mathrm{mmHg}, p=0.001)$ was found.

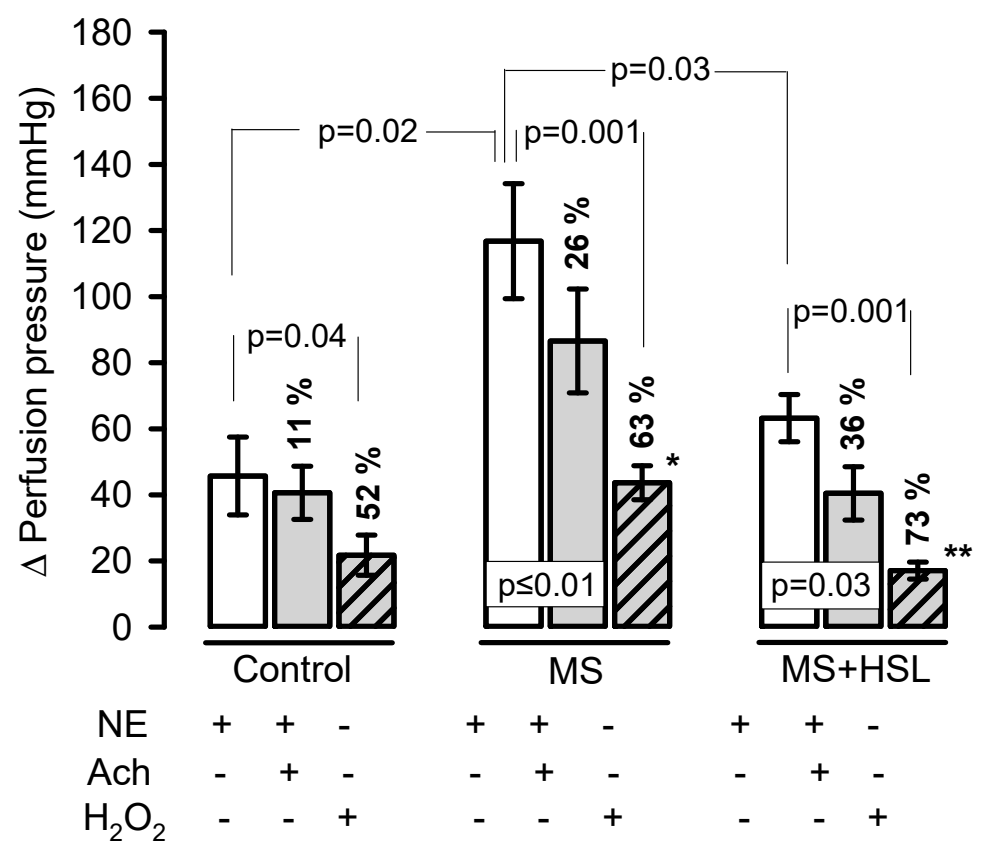

Figure 2. Changes the $\Delta$ of the PP in the isolated kidney. The control, MS, and MS + HSL. rats were perfused with NE $20 \mu \mathrm{M}$, in presence of (Ach $20 \mu \mathrm{M}$, and finally in presence of $1.7 \mu \mathrm{M}$ of $\mathrm{H}_{2} \mathrm{O}_{2}$. Data are expressed as changes the delta $(\Delta)$ of the PP in mmHg. After each perfusion bolus, the kidneys were washed for a period of $20 \mathrm{~min}$ with Krebs solution, to allow them to return to the basal PP (75-90 mmHg). Statistically significant at ${ }^{*} p=0.01$ control vs. MS and ${ }^{* *} p=0.001$ MS + HSL vs. MS. Abbreviations: Ach = acetylcholine, NE = norepinephrine, MS = metabolic syndrome, MS + HSL = metabolic syndrome plus Hibiscus sabdariffa L., PP = pressure perfusion. Data are expressed in means $\pm \mathrm{SE}$, $(n=8$, rats in each group). Statistical significance was determined by one-way ANOVA test, followed by Tukey's post hoc test.

\section{Antioxidant Enzymes}

Figure 3A,B shows the activity of the SOD isoforms. Panel A shows the SOD-Mn activity in the kidney homogenate of the experimental groups. In rats with MS, a decrease in SOD-Mn activity was observed when compared to the control and MS + HSL. groups ( $p=0.02$ and $p=0.04$, respectively). On the other hand, the SOD-Cu/Zn activity only 
showed significant changes between the MS rats and the rats of the MS + HSL. group $(p=0.04)$.
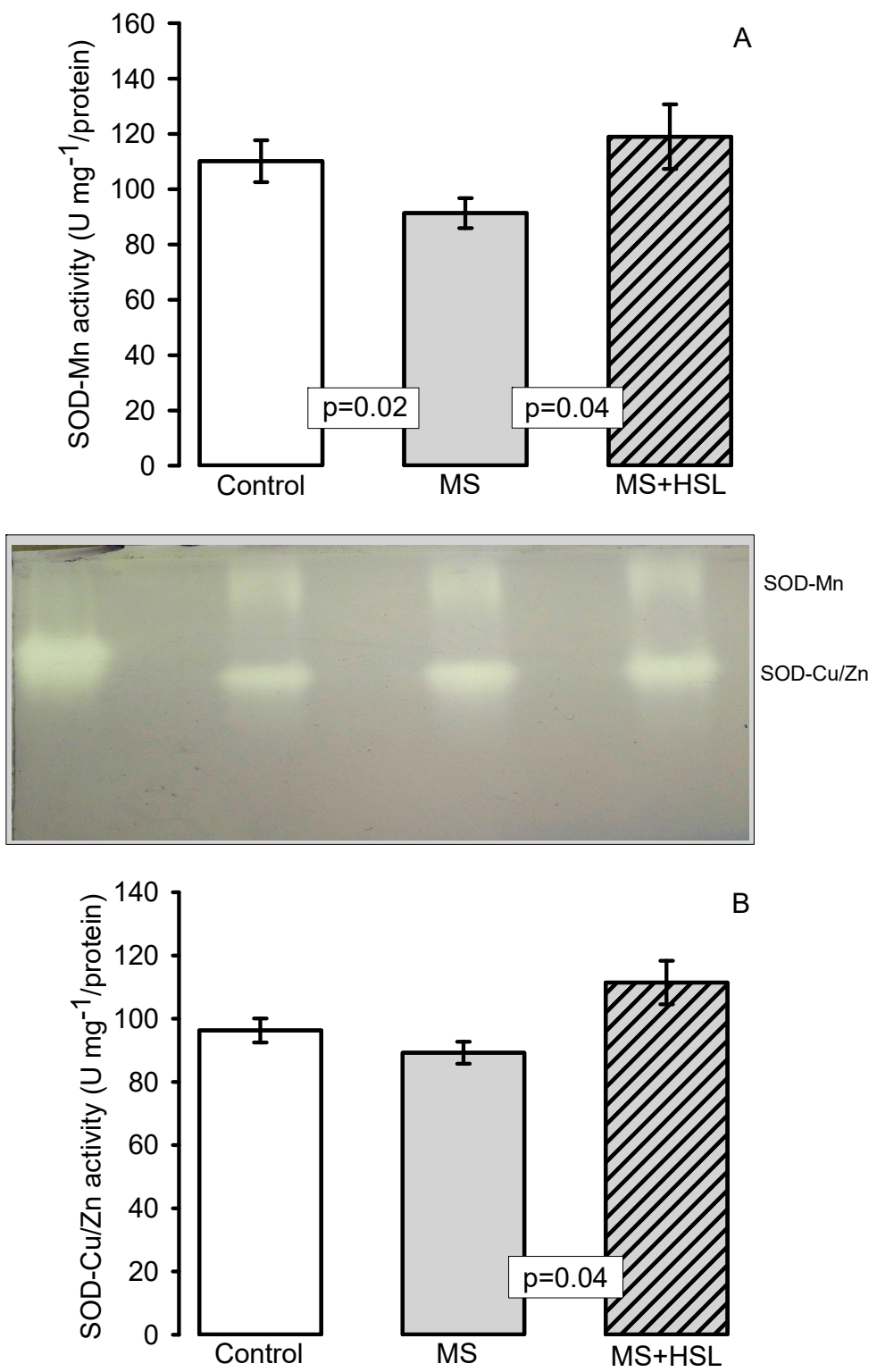

B

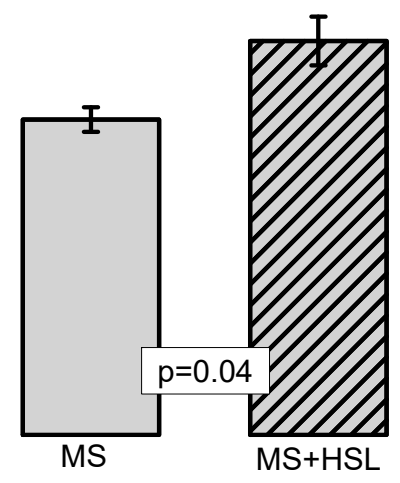

Figure 3. Histogram representing the densitophotometric analysis of the activity of the superoxide dismutase (SOD) isoforms in the kidney homogenates of the experimental rats. A representative native gel of the activities of the SOD-Mn, and SOD-Cu/Zn electrophoresis is shown between the graphs $\mathrm{A}$ and $\mathrm{B}$ is shown. (A) Mn isoform, and (B) $\mathrm{Cu} / \mathrm{Zn}$ isoform. Abbreviations: MS = metabolic syndrome, MS + HSL. = metabolic syndrome plus Hibiscus sabdariffa L., Mn = Manganese, $\mathrm{Cu} / \mathrm{Zn}=$ Copper/Zinc Data are expressed in means $\pm \mathrm{SE},(n=8$, rats in each group). Statistical significance was determined.

Figure 4 shows the CAT activity, where no significant differences in any of the experimental groups were found. 


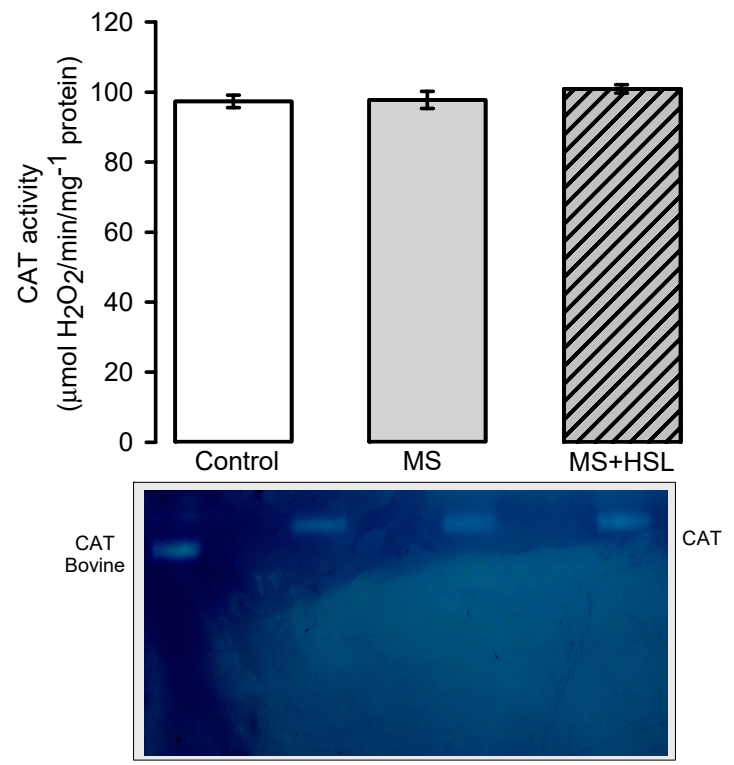

Figure 4. Densitophotometric analysis of the activity of catalase in the kidney homogenate. Below the histogram, a native representative gel of the CAT activity is included. Abbreviations: CAT = catalase, MS = metabolic syndrome, MS + HSL. = metabolic syndrome plus Hibiscus sabdariffa L., Data are expressed in means $\pm \mathrm{SE}$, $(n=8$, rats in each group).

Figure 5A shows the GST activity which was significantly lower in the MS rats compared to that found in the control rats $(p=0.001)$. However, between the MS + HSL. vs. MS only a tendency to an increase was observed without reaching a statistically significant difference. Figure 5B shows the GR activity, in which there was a significant decrease in the MS rats when compared to the control and MS + HSL rats $(p=0.01)$.
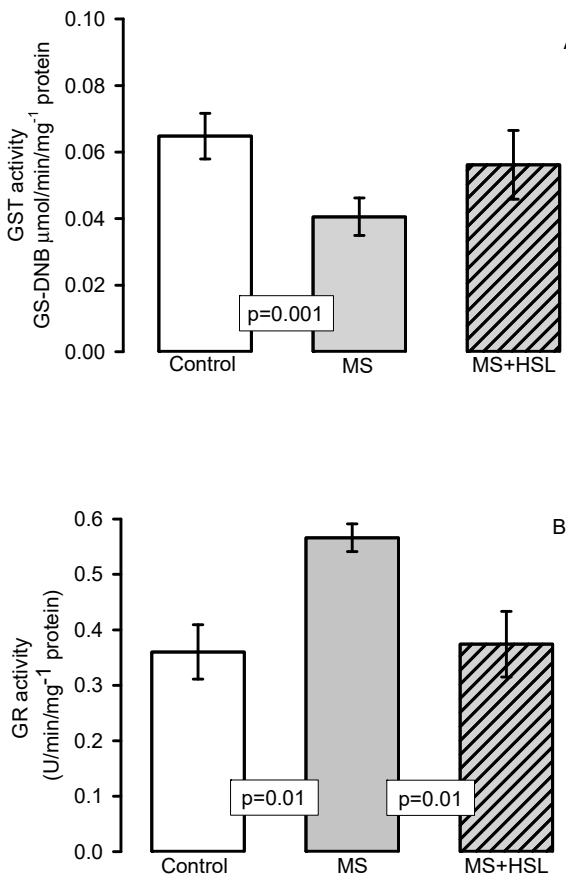

Figure 5. Effect of the HSL treatment on glutathione-S-transferase activity (panel A) and glutathione reductase (GR) activity (panel B) in kidney homogenate. Abbreviations: MS = metabolic syndrome, MS + HSL = metabolic syndrome plus Hibiscus sabdariffa L., GST = glutathione-S-transferase, $\mathrm{GR}=$ glutathione reductase. Data are expressed in means $\pm \mathrm{SE},(n=8$, rats in each group). Statistical significance was determined by one-way ANOVA test, followed by Tukey's post hoc test. 
Figure $6 \mathrm{~A}, \mathrm{~B}$ show the activity of peroxidases and GPx, respectively (Panel (A) by native gels and panel (B) by spectrophotometry). The peroxidase and GPx activities were determined by both techniques and showed a significant decrease in the MS rats in comparison with those found in the control and MS + HSL. groups $(p=0.02, p=0.001$ and $p=0.01, p=0.05$ respectively).

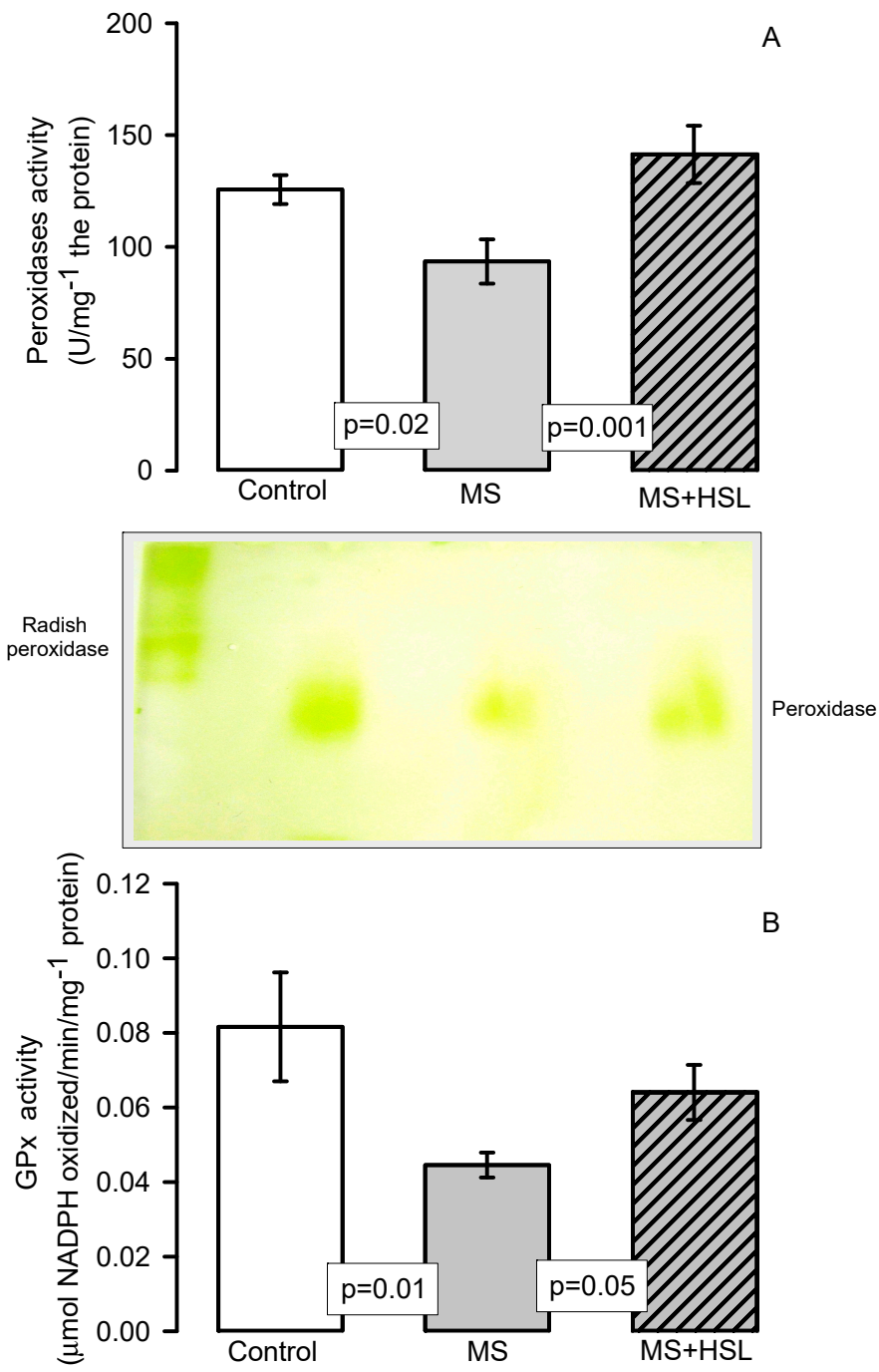

Figure 6. Peroxidase activity (A) and GPx activity (B). Panel (A) densitophotometric analysis of the activities of peroxidases, a representative native gel is shown below the histogram. Where peroxidases are present, the gel remains transparent and the 3,3,5,5-tetramethylbenzidine is oxidized, showing a green coloration. Abbreviations: MS = metabolic syndrome, $\mathrm{MS}+\mathrm{HSL}=$ metabolic syndrome plus Hibiscus sabdariffa L., GPx = glutathione peroxidase. Data are expressed in means $\pm \mathrm{SE},(n=8$, rats in each group). Statistical significance was determined by one-way ANOVA test, followed by Tukey's post hoc test.

The OS indicators in the kidney homogenate are shown in Table 3. There was a significant increase in LPO and in the carbonylation levels $(p \leq 0.001)$ and there were decreases in the $\mathrm{NO}_{3}{ }^{-} / \mathrm{NO}_{2}{ }^{-}$ratio, GSH, TAC and Vit $\mathrm{C}$ levels $(p \leq 0.03$ and $p=0.05$ respectively) in the MS group in compared to the control group. The HSL treatment resulted in a decrease in $\mathrm{LPO}(p=0.01)$ but an increase in $\mathrm{NO}_{3}{ }^{-} / \mathrm{NO}_{2}{ }^{-}$ratio, $\mathrm{GSH}$ and Vit $\mathrm{C}$ levels ( $p=0.001, p=0.01$ and $p=0.05$ respectively) in comparison with the MS group. 
Table 3. Oxidative stress indicators in the kidney homogenate in the experimental groups.

\begin{tabular}{cccc}
\hline Variables (mg of Protein) & Control & MS & MS + HSL. \\
\hline LPO (MDA nmol) & $0.34 \pm 0.05$ & $0.56 \pm 0.03^{* * *}$ & $0.45 \pm 0.05^{++}$ \\
\hline Carbonylation (ng carbonyls) & $0.07 \pm 0.00$ & $0.11 \pm 0.01^{* * *}$ & $0.08 \pm 0.01$ \\
\hline $\mathrm{NO}_{3}{ }^{-}$and $\mathrm{NO}_{2}{ }^{-}(\mathrm{nM})$ & $0.09 \pm 0.00$ & $0.06 \pm 0.01^{+}$ & $0.10 \pm 0.0{ }^{\S}$ \\
\hline GSH $(\mu \mathrm{mol})$ & $0.0014 \pm 0.0001$ & $0.0009 \pm 0.0001^{+}$ & $0.0013 \pm 0.0000^{* *}$ \\
\hline TAC (Trolox nmol) & $0.61 \pm 0.01$ & $0.57 \pm 0.01^{+}$ & $0.60 \pm 0.01$ \\
\hline Vit C $(\mu \mathrm{M})$ & $0.021 \pm 0.002$ & $0.015 \pm 0.001^{*}$ & $0.018 \pm 0.000^{*}$ \\
\hline
\end{tabular}

Data are mean \pm SE, $n=8$ each group. Statistically significant at ${ }^{* * *} p \leq 0.001$ control vs. MS, ${ }^{\dagger} p \leq 0.03$ control vs MS, ${ }^{\S} p \leq 0.001$, MS + HSL vs. MS. ${ }^{* *} p=0.01$ MS + HSL vs. MS, ${ }^{*} p=0.05$ control MS + HSL vs. MS, ${ }^{+\dagger} p=0.01$ MS + HSL vs. MS. Abbreviations: MS = metabolic syndrome; MS + HSL = metabolic syndrome plus Hibiscus sabdariffa L., Statistical significance was determined by one-way ANOVA test, followed by Tukey's post hoc test.

\section{Discussion}

MS claims the lives of thousands of people every year around the world and therefore the search for new alternative and accessible treatments for this disease is of the greatest interest. OS plays an important role in the pathophysiology of MS, resulting in cellular damage and in hemodynamic alterations which affect the function of the kidney in the long term [2]. Several studies have focused on the use of traditional medicine to counteract the damage caused by ROS. In particular, the infusion with HSL has shown to decrease the OS in the liver and heart in MS rats [19]. Therefore, the aim of this work was to evaluate the effect of a $2 \%$ HSL infusion on renal function in a MS rat model. MS was induced by the administration of $30 \%$ sucrose in drinking water. We also determined the level of some components of the antioxidant system in the kidney homogenate.

\subsection{Physiological Characteristics of the MS Model}

The MS rat model courses with high systolic blood pressure (SBP), hypertriglyceridemia, obesity (intra-abdominal deposits of fat), hyperinsulinemia, and insulin resistance (IR) [19]. However, the HSL infusion decreased body weight, intra-abdominal fat, TG, insulin, HOMA index (IR marker), and leptin in the MS rats. This effect is attributed to the polyphenols, and flavonoids present in HSL. These antioxidant molecules have hypolipidemic effects inhibiting the accumulation of fat by reducing oxysteroles through the metabolism of bile acids. These components of HSL can block the lipid accumulation in the liver, adipose tissue and they can increase the palmitic acid excretion in the feces [20]. They increase the $\beta$-oxidation of fatty acids by inhibiting the fatty acid synthase, 3-hydroxy3-methylglutaryl coenzyme A reductase, acyl-coenzyme A, and cholesterol acyltransferase, thus improving insulin sensitivity and reducing the TG levels [16]. Furthermore, the loss of intra-abdominal fat and the decrease in TG levels caused by the HSL infusion can be due in part, to the decrease in lipogenesis due to + / - hydroxycitrate $(+/-\mathrm{HCA})$ that is transformed into - / - HCA. HCA inhibits the extra-mitochondrial enzyme ATP-citratelyase which catalyzes the breakdown of citrate to obtain oxaloacetate and acetyl-CoA. This is an important step for the synthesis of fat. However, these components can also inhibit the formation of malonyl-CoA that stimulates the activity of carnitine transferase leading to decreases in lipogenesis and increases the lipids oxidation and/or glycogenesis [21].

Leptin is an adipocytokine involved in energy expenditure, inflammation, lipid metabolism and glucose metabolism. Hyperlipidemia is positively associated to IR and to an increase in the intra-abdominal fat accumulation [22]. The treatment with the HSL infusion decreased leptin levels, suggesting that it may influence the synthesis leptin in adipose tissue [19]. A recent study showed that the administration of an HSL extract decreased the leptin mRNA levels in intra-abdominal adipocytes. Another study showed that the administration of the HSL in MS patients, reduced leptin levels [23].

In addition, IR, and hyperinsulinemia lead to structural abnormalities in the kidney, such as increased tubulointerstitial damage, fibrosis, and mesangial proliferation. These 
changes modify renal hemodynamics [24]. Our results show that the treatment with the HSL infusion decreased the insulin levels and the HOMA index in MS rats. This effect may be due to the presence of cyanidin-3-glucoside which can over express the GLUT4 transporter and may increase the signaling of insulin in the cells [25].

Furthermore, the MS rats showed hypertension and the $2 \%$ HSL infusion treatment decreased SBP. The antihypertensive effects of HSL may be due to anthocyanins (delphinidin3-O-sambubiosides and cyanidin-3-O-sambubioside) through different mechanisms. The first is the diuretic effect of these molecules that resembles that of aldosterone by increasing the elimination of water and sodium. The second mechanism could be by the inhibition of angiotensin converting enzyme 2 (ACE2) [26]. In addition to the antihypertensive effect of anthocyanins and polyphenols, these molecules can also induce the phosphorylation of eNOS in endothelial cells which contributes to decrease blood pressure [27]. Also, the administration of $2 \%$ HSL infusion in MS rats increased the secondary metabolites of nitric oxide $(\mathrm{NO})$, the $\mathrm{NO}_{3}{ }^{-} / \mathrm{NO}_{2}{ }^{-}$ratio. This suggests that these metabolites may be derived from the eNOS pathway and may contribute to the improvement of the endothelial function and the decrease in SBP. In this sense, the polyphenols present in HSL can activate the PI3K pathway in the endothelium and regulate NO through the phosphorylation of eNOS and the suppression of the mobilization of $\mathrm{Ca}^{2+}$, thus increasing vasorelaxation [28]. However, the protocatechuic acid is a potential inhibitor of the iNOS pathway [29].

\subsection{Effect of a $2 \%$ HSL Infusion on the Kidney Function in MS}

The MS rats showed deterioration of the renal function evidenced by an elevation of the levels of SCr, by albuminuria, by lowering $\mathrm{CCr}$ and by renal histological changes. Retracted glomerular tuft, fibrosis, and the increased urinary space with detritus were present. There are alterations in the renin angiotensin aldosterone system in MS, which are one of the main causes of the deterioration of the renal function. Changes in this system result in an increase in the intraglomerular pressure and filtration rate. These changes lead to an increase in SCr, albuminuria and a decrease in CCr [30]. However, The HSL infusion treatment improved renal function by lowering the concentration of SCr, and albuminuria, and by increasing CCr. The epithelial mesenchymal transition of human diabetic tubular cells promotes the generation of fibroblasts and favors fibrosis via up-regulation of AT -1 and the downstream TGF- $\beta 1$ pathway. The polyphenols present in HSL attenuate the renal epithelial mesenchymal transition [31]. Administration of HSL in mice with renal damage caused by doxorubicin or adenine had decreased proteinuria, SCr and increased the CCr [32]. This HSL benefic effect has been associated to anthocyanins. These molecules inhibit the production of angiotensin II, and lead to an increase in the glomerular filtration rate [33]. HSL also contains quercetin and eugenol which are potent vasodilators that increase renal flow through increased levels of NO, produced via the eNOS pathway. In obese and diabetic rats with nephropathy, HSL administration decreases albuminuria and increases the CCr. These beneficial changes are associated to the preservation of the structural anatomy of the glomerulus [34]. Our results show that the treatment with HSL decreased the histopathological changes and improved renal function in the kidney of the MS rats. In addition, the administration of HSL in drinking water to mice with lipopolysaccharide-induced kidney inflammation, reduced histological changes such as tubular inflammation [18]. The administration of 5 and 10\% the HSL extract in rats with adenine decreased inflammation and renal and interstitial tubule fibrosis [35].

\subsection{Renal Vascular Resistance}

The results in the isolated and perfused kidney showed that NE perfusion in MS rats was increased and there was an elevation in the $\Delta$ of PP. This could be due to the histopathological changes, to the loss of the renal function and to an increase in the $\alpha$ adrenergic receptors. An elevation in these receptors leads to the alteration of the vascular reactivity in the afferent artery, causing an increase in renal vascular resistance [36]. NE acts by inhibiting the antihypertensive mechanisms including the release of renin, the 
elevation of natriuretic pressure, and the decrease in the release of the renal medullary depressant hormone [37]. However, HSL treatment in MS rats showed that the $\Delta$ of PP was lower when NE was perfused. This suggests that the HSL infusion decreases vascular resistance, probably by inhibiting the sensitivity of $\alpha$-adrenergic receptors. In this sense, a decrease in the vasoconstrictive response in the presence of $\mathrm{NE}$ is present in isolated aortas from diabetic rats treated with an HSL extract [26]. Furthermore, an infusion of HSL showed a decrease the negative inotropic effect in isolated hearts of rats, probably through $\alpha$-adrenergic receptors, and this was associated with a decrease in SBP.

Besides, the perfusion with NE+Ach decreased the percentage of the $\Delta$ of PP in the kidney of the rats treated with HSL in a $36 \%$ when compared to the MS rats in which it was of $26 \%$. These results suggest the presence of endothelial damage in the renal vasculature in MS rats. They also suggest the beneficial effect of the HSL infusion on renal vascular reactivity by decreasing the $\Delta$ of PP. This is reflected in a decrease in renal vascular resistance. Previous studies demonstrated that this MS model courses with endothelial dysfunction, hyper contractility to NE and loss of Ach- dependent vasorelaxation in the aorta but that HSL treatment improved this condition [19]. In addition, these results can also be associated with the increase in the glomerular filtration rate and the level of CCr in the MS + HSL. group. These beneficial effects of the HSL infusion can also be caused by the mediation of vasorelaxing mechanisms, by the inhibition of the ECA2, by a decrease of $\mathrm{Ca}^{2+}$ levels in vascular smooth muscle, by increases in NO via eNOS pathway and by a decrease in flux due to cholinergic and/or histaminergic factors [16,17].

The $\mathrm{NE}+\mathrm{H}_{2} \mathrm{O}_{2}$ perfusion showed a decrease in the $\Delta$ of $\mathrm{PP}$ of $63 \%$ in MS rats; however, in the rats treated with the HSL infusion the decrease was of $73 \%(p=0.001)$. These results suggest that MS rats' course with OS, as has already been reported [38] and that the HSL infusion decreases this oxidant state. In this sense, $\mathrm{H}_{2} \mathrm{O}_{2}$ can have a dual effect by modulating vascular reactivity, and by a vasodilator effect in the sub mucosal arterioles [39]. Therefore, the effect depends on the vascular bed in which it is acting [40] and upon the physiological and pathological conditions [41]. The effect also depends on the concentration; at 10-100 nM, it has beneficial effects on the vascular reactivity; however, at high concentrations of $1 \mu \mathrm{M}$ it induces vasoconstriction, inflammation, and cell death [42]. A study reported that low concentration of $\mathrm{H}_{2} \mathrm{O}_{2}$ activate 4-aminopyridine-sensitive potassium channels that lead to the closure of voltage-dependent $\mathrm{Ca}^{2+}$ channels. This causes hyperpolarization, which then leads to relaxation of arterial smooth muscle. However, increased OS impairs the capacity of $\mathrm{H}_{2} \mathrm{O}_{2}$ to exert its vasorelaxing effect [40]. $\mathrm{H}_{2} \mathrm{O}_{2}$ infused into the renal artery causes massive transient proteinuria [38]. A high production of $\mathrm{H}_{2} \mathrm{O}_{2}$ which acts as a potent renal vasoconstrictor [43], leads to hypertension in diabetic mice and rats [44]. This suggests that there is an excessive production of $\mathrm{H}_{2} \mathrm{O}_{2}$ in MS that contributes to renal damage. The excessive production of $\mathrm{H}_{2} \mathrm{O}_{2}$ may explain the differences in the response of the $\Delta$ of PP. It may also be involved in the generation of the histopatological changes, glomerular hemodynamics, proteinuria, and hypertension which are present in the kidney of the MS rats.

\subsection{Oxidant/Antioxidant Effect of the HSL Infusion}

Our results show that there is a decrease in the activity of the enzymes SOD-Mn, peroxidases and GPx in the kidney of MS rats. These enzymes are associated with antioxidant defenses [45]. SOD-Cu/Zn did not show a significant difference, and this suggests a possible damage to the mitochondria in the kidney cells. This antioxidant enzyme (SOD-Mn) is located in the mitochondrial matrix and participates in the dismutation of the $\mathrm{O}_{2}{ }^{-}$to $\mathrm{H}_{2} \mathrm{O}_{2}$ [46]. A decrease in the SOD activity is associated with MS regardless of cellular aging, OS markers and dietary risk factors. It even acts as a predictor of this syndrome [47]. Inhibition of SOD increases vascular OS and alters the endothelium-dependent vasoreactivity [48]. In mice lacking an isoform of SOD such as the extracellular isoform, there are increased amounts of ROS and alterations in vascular reactivity [49]. Down-regulation of SOD-Mn in MS rats and the subsequent excessive release of $\mathrm{O}_{2}{ }^{-}$and $\mathrm{H}_{2} \mathrm{O}_{2}$ contribute to 
the inflammatory, proliferative, and fibrotic renal injury. However, the treatment with the HSL infusion increased the activity the two SOD isoforms. The polyphenols present in the HSL may neutralize ROS by donating an electron or hydrogen atom. They act as chelators and exert co-antioxidant activity with essential vitamins. They inhibit the xanthine oxidase and can also up-regulate SOD, GPx and peroxidase isoforms through the regulation of the Nrf2/Keap1 pathway. Furthermore, flavonoids are another type of molecule presents in HSL that could increase the activity of these enzymes [50]. The results suggest that the $2 \%$ HSL treatment increases the activity of SOD isoforms in the kidney, thus contributing to reduce OS in MS rats and to improve the kidney function. A recent study showed that the beneficial effect of the polyphenols present in HSL can be due to a lower generation of $\mathrm{H}_{2} \mathrm{O}_{2}$ in the arterioles. $\mathrm{H}_{2} \mathrm{O}_{2}$ interacts exogenously with endothelial cell, and penetrates through aquaporins inhibiting phosphatases, NADPH oxidases and activating Nrf2 [41]. However, the increase in the activity of the SOD isoforms could lead to an increase in the endogenous $\mathrm{H}_{2} \mathrm{O}_{2}$ in the kidney.

The activity of the SOD isoforms is related to the activity of other antioxidant enzymes such as CAT, GPx and peroxidases [51]. These enzymes are responsible for the elimination of the $\mathrm{H}_{2} \mathrm{O}_{2}$ which results from the activity of the SOD isoforms. The activity of these enzymes decreases OS in MS. GPx are the most efficient for the detoxification and removal of intracellular $\mathrm{H}_{2} \mathrm{O}_{2}$ and organic peroxides. CAT depends on the gradient and concentration of $\mathrm{H}_{2} \mathrm{O}_{2}$ [52]. Our results show that the activity of CAT did not show significant differences in the kidney of MS rats and therefore, the HSL treatment did not modify its activity. GPx do not depend on the concentration gradient but on the presence of NADPH and GSH for the conversion of $\mathrm{H}_{2} \mathrm{O}_{2}$ to $\mathrm{H}_{2} \mathrm{O}$ [19]. Therefore, they have a better antioxidant capacity to detoxify the $\mathrm{H}_{2} \mathrm{O}_{2}$ than CAT [53]. The GPx are predominantly localized in the renal tubules and an increase in their activity contributes to decrease the concentration of ROS and to improve renal blood flow [54]. The increase in the activities of both GPx and peroxidases by the HSL infusion suggests that this treatment modulates the activity of these enzymes. Therefore, it favors an increase in the activity of these enzymes, thus contributing to the decrease of chronic OS in the kidney of the MS rats. This beneficial effect of the infusion may be associated to the effect of resveratrol and polyphenols [55]. Peroxidases may lower the increase in $\mathrm{H}_{2} \mathrm{O}_{2}$ in patients with MS. An inhibition of the activity of peroxidases diminishes endothelial damage and severe proteinuria and may result in damage to the renal function [11].

GST is the enzyme involved in the metabolism of xenobiotics and in the protection against damage caused by peroxidized. It catalyzes the ionization of GSH to a nucleophilic thiolate anion form which reacts spontaneously with nucleophilic components that are located close nearby such as $\alpha, \beta$-unsaturated aldehydes. This reaction is followed by the conjugation of GSH. This conjugation increases the solubility of the toxic products, facilitating their excretion from the cell. The GST activity decreases the LPO rate [19]. Our results show that the GST activity was decreased in the kidney of MS rats. The IR and hyperinsulinemia present in MS can contribute to the GST inhibition [19]. In this sense, the GSTA4 expression is down regulated in the adipose tissue from obese insulin- resistant C57BL/ 6 mice and in humans with obesity and IR [56]. Moreover, a decrease in GST activity has been related to an increase in ROS in arterial hypertension [57]. However, the HSL treatment showed a tendency to increases the GST activity. This suggests that the decreased GST activity in the kidney of the MS rats favors OS.

The damage caused by OS is evidenced by the increase in LPO and carbonylation and by the decrease of the TAC and GSH. The HSL treatment decreased these damages. The antioxidant properties of the HSL on GST activity and on GSH have been attributed to phenolic compounds such as anthocyanin and protocatechuic acid. GSH contributes to the decrease LPO and carbonylation which in turn, increases the GSH and TAC in the kidney. In the aortic aneurysm of Marfan syndrome patients, the infusion of $2 \%$ HSL increased GST activity, GSH and TAC concentration but LPO and carbonylation levels were decreased [50]. These effects might be due to polyphenols present in the HSL which 
have a benzoic ring with one or more hydroxyl groups that participate as scavengers of ROS They also participate in a second line of defense when they have not been neutralized by the enzymatic antioxidant system [55]. This suggests that polyphenols can contribute to increase the antioxidant capacity of the non- enzymatic system, favoring an increase of TAC and GSH and a decrease in LPO and carbonylation levels in the kidney of MS rats. The TAC is considered as a reliable indicator of the antioxidant content and it depends on the enzymatic and non-enzymatic antioxidant system in which GSH participates. In this sense, GSH is the most versatile antioxidant since it has a variety of functions that include the detoxification of xenobiotics or their metabolites. It is the largest source of endogenous antioxidants, and it inhibits the radicals $\mathrm{OH}^{-}, \mathrm{O}_{2}{ }^{-}$. It regenerates vitamins $\mathrm{C}$ and E, reconverting them to their active forms. It acts as a cofactor for the GPx and GST and as a substrate of GR. It is transported by amino acids through the plasma membrane acting as a storage source of cysteine. Eighty-five percent of the total cellular GSH is free, and the rest is bound to proteins [44]. Our results show that the GSH levels were increased by the HSL treatment. This effect may be due to the increase in the genetic expression of $\gamma$-glutamyl-cysteine synthetase and GSH synthetase caused by HSL. This enzyme is responsible for the de novo synthesis of GSH [56].

For its part, GR is the enzyme that catalyzes the reaction by which oxidized glutathione (GSSG) is reduced to GSH using $\mathrm{NADPH}^{+}$as an energy source. GR was the only enzyme that was increased in the kidney of rats with SM. This may be due to the OS that is associated with the decrease in the GSH concentration and that results in a compensatory mechanism that is aimed to increase GSH levels $[57,58]$. However, the increase of the GSH levels by the HSL treatment decreases the activity this enzyme.

In addition, Vit $C$ contributes to the increase in TAC. This vitamin is water- soluble having a potent antioxidant effect in vivo. Its basal concentration in plasma is within the $\mu \mathrm{M}$ range. However, its concentration is decreased in the presence of OS [59]. Our results show that the concentration of Vit $\mathrm{C}$ in the kidney was lower in MS and that the HSL treatment increased its concentration. The calyces of HSL are rich in organic acids such as citric and ascorbic acid [16]. The input of Vit C by the infusion of HSL favors the elevation of the levels of this vitamin and contributes to GSH regeneration, which favors the reduction of LPO and carbonylation.

\section{Material and Methods}

\subsection{Animals}

The experiments with laboratory rats were approved by the Laboratory Animal Care Committee of our institution and were conducted in compliance with the Guide for the Care and Use of Laboratory Animals of NIH. Eight male 250-300 g weight rats were used per each of the following groups: group 1 control, group 2 MS with 30\% sucrose in their drinking water for 12 weeks and Group 3 MS with 30\% sucrose and an HSL infusion (MS + HSL. ) at the concentration of $20 \mathrm{~g} / \mathrm{L}(2 \%)$. The animals were housed in ad hoc plastic boxes (Nalgene, New York, NY, USA) and were subjected to $12 \mathrm{~h}$ light/obscurity cycles and environmental temperature between 18 and $26^{\circ} \mathrm{C}$. The rats were fed commercial rodent pellets (LabDiet 5008, PMI Nutrition International, Inc., Richmond, IN, USA). Rodent commercial food for rodents that contained $23 \%$ of crude protein, $4.5 \%$ of crude fat, $8 \%$ of ashes, and $2.5 \%$ of added minerals) ad libitum. At the end of the experimental period, the rats were weighed, and their systolic blood pressure (SBP) was determined using a tail cuff attached to a pneumatic pulse transducer (Narco Bio-Systems Inc., Houston, TX, USA), in compliance with the method described by Pérez-Torres et al. [60].

\subsection{HSL Infusion}

The HSL calyces were acquired in Chilapa de Alvarez (high zone from Guerrero, Mexico). The infusion was prepared as follows: $20 \mathrm{~g}$ of the HSL calyces was added to a liter of boiling $\left(95-100{ }^{\circ} \mathrm{C}\right)$ drinking water for $10 \mathrm{~min}$ and then left to cool. $300 \mathrm{~g}$ sucrose was added. The solution was filtered and stored at $4^{\circ} \mathrm{C}$ until used [60]. Total estimation 
of vitamin $C$ in the infusion was determined by the method of Jagota [61]. For this determination, $100 \mu \mathrm{L}$ of the HSL infusion were added to $200 \mu \mathrm{L}$ of Folin-Ciocalteu reagent $0.20 \mathrm{mM}$. The mixture was shaken vigorously in a vortex for $5 \mathrm{~s}$ and incubated for $10 \mathrm{~min}$. The absorbance was measured at $760 \mathrm{~nm}$. The calibration curve was obtained using an ascorbic acid standard solution. Total flavonoid content in the infusion was determined by the method of Jia [62]. $100 \mu \mathrm{L}$ of HSL infusion were added to $2175 \mu \mathrm{L}$ of distilled $\mathrm{H}_{2} \mathrm{O}$ plus $75 \mu \mathrm{L}$ of $5 \% \mathrm{NaNO}_{2}$ and incubated for $3 \mathrm{~min}$. Then, $150 \mu \mathrm{L}$ of $10 \% \mathrm{AlCl}_{3}$ were added, and the solution was incubated for $5 \mathrm{~min} .0 .5 \mathrm{~mL}$ of $1 \mathrm{M} \mathrm{NaOH}$ were added to the mixture and it was shaken vigorously in vortex. The absorbance was measured at $510 \mathrm{~nm}$. The calibration curve was obtained using quercetin as a standard. To determine total anthocyanin content in the infusion, $100 \mu \mathrm{L}$ were added to $50 \mathrm{~mL}$ of buffers $\left(\mathrm{NaC}_{2} \mathrm{H}_{3} \mathrm{O}_{2}, 4 \mathrm{M}\right)$ at $\mathrm{pH} 1$ and 4.5 , respectively, and the absorbance was measured at 520 and $700 \mathrm{~nm}$ and compared against a blank cell, filled with distilled $\mathrm{H}_{2} \mathrm{O}$. The difference in the absorbance was used for calculating the cyanidin-3-glucoside (total monomeric anthocyanin) as described by the method of Lee [63]. The $\%$ HSL infusion contained $1.13 \pm 0.12 \mathrm{mM}$ of vitamin C, $12.37 \pm 0.42 \mathrm{mg} / \mathrm{L}$ of quercetin and $101 \pm 49 \mathrm{mg} / \mathrm{L}$ of cyanidin-3-glucoside.

\subsection{Albuminuria and Creatinine Depuration}

Albuminuria was measured using the bromocresol green reagent [64]. Urine and serum creatinine (UCr and SCr respectively) was measured by the Jaffe method [65] and glomerular filtration was calculated according to the following formula: clearance creatinine $(\mathrm{CCr})=[\mathrm{UCr}] /[\mathrm{SCr}] \times$ urinary volume $(24 \mathrm{~h}) /$ time $(1440 \mathrm{~min})$.

\subsection{Isolated Perfused Kidney}

The right kidney was exposed by a midline laparotomy, and the mesenteric and right renal arteries were cleared of surrounding tissue. The right renal artery was cannulated through the mesenteric artery to avoid interruption of blood flow; and the kidney was removed, suspended, and perfused at constant flow by means of a peristaltic pump (MasterFlex Easy-load II, number 77,200-50; Cole-Parmer Instrument Co, Vernon Hills, IL, USA) with Krebs solution at $37{ }^{\circ} \mathrm{C}$ and oxygenated with $95 \% \mathrm{O}_{2} / 5 \% \mathrm{CO}_{2}$. The solution had the following composition (mM/L): $118 \mathrm{NaCl}, 1.2 \mathrm{NaH}_{2} \mathrm{PO}_{4}, 25 \mathrm{NaHCO}_{3}, 4.7 \mathrm{KCl}$, $1.2 \mathrm{CaCl}_{2}, 4.2 \mathrm{MgSO}_{4}$, and 5.5 glucose (pH 7.4). Flow was adjusted to a basal perfusion pressure (PP) of 75 to $90 \mathrm{mmHg}$. Mean flow rate of the perfusing solution was 8 to $9 \mathrm{~mL} / \mathrm{min}$. PP was measured with a transducer (Grass Telefactor, Grass Technologies, Astro Med, West Warwick, RI, USA), captured, and recorded by means of a Grass model polygraph 79D and an online program (Grass PolyView Data Acquisition and analysis version 2.0), in compliance with the method described by Pérez-Torres et al. [66]. After a period of $20 \mathrm{~min}$ of equilibrium, we proceeded to administer boluses of vasoconstrictors and vasodilators, which were given for sufficiently long intervals to allow the PP to return to baseline (between 75 and $90 \mathrm{mmHg}$ ). The sequences and concentrations of the boluses were: norepinephrine (NE) $20 \mu \mathrm{M}, \mathrm{NE} 20 \mu \mathrm{M}$ plus acetylcholine (Ach) $20 \mu \mathrm{M}$, and finally NE $20 \mu \mathrm{M}$ plus $1.7 \mu \mathrm{M}$ of $\mathrm{H}_{2} \mathrm{O}_{2}$.

Changes in the PP produced by the NE, NE+Ach and $\mathrm{NE}+\mathrm{H}_{2} \mathrm{O}_{2}$ were calculated by taking the mean of the pulsatile traces before the administration and the mean of the traces at the maximal PP value after administration. Data are expressed as changes delta $(\Delta)$ of PP in mmHg. After each perfusion bolus, the kidneys were washed for a period of $20 \mathrm{~min}$ with Krebs solution, to allow it to return to the basal PP $(75-90 \mathrm{mmHg})$, and no sign of tachyphylaxis was present.

\subsection{Serum Sample}

The abdominal aorta was exposed by midline laparotomy and cannulated to obtain $4 \mathrm{~mL}$ of blood, taking care to avoid hemolysis. The blood was centrifuged for $20 \mathrm{~min}$ at $936 \mathrm{~g}$ and at $4{ }^{\circ} \mathrm{C}$, in order to collect the serum in aliquots of $400 \mathrm{~mL}$ and stored at $-30{ }^{\circ} \mathrm{C}$. 


\subsection{Biochemical Variables}

Commercial kits were used for the determination of some serum biochemical variables in the rats. Glucose concentration was determined by enzymatic SERA-PAKR Plus kit (Bayer Corporation, S'ees, France). TC and TG determinations were made using commercial enzymatic kits, (RANDOX Laboratories Ltd., Crumlin, County Antrim, UK). Leptin and insulin were determined using commercial radioimmunoassay kits (RIA) (Linco Research Inc., Saint Charles, MO, USA). The HOMA index of resistance to insulin was calculated. HOMA $-\mathrm{IR}=$ insulin $\mu \mathrm{U} / \mathrm{mL} \times$ glucose $\mathrm{mM} / \mathrm{L} / 225$.

\subsection{Kidney Homogenate}

The left kidney was dissected and washed with $0.9 \%$ saline solution and immediately perfused with a sucrose buffer ( $25 \mathrm{mM}$ sucrose, $10 \mathrm{mM}$ Tris, $1 \mathrm{mM}$ EDTA, and $\mathrm{pH}$ 7.35). The capsule was removed, and the kidney was homogenized in the same sucrose buffer with protease inhibitors ( $1 \mathrm{mM}$ PMSF, $2 \mu \mathrm{M}$ pepstatin, $2 \mu \mathrm{M}$ leupeptin, and $0.1 \%$ aprotinine). The homogenate was kept in ice. The kidney homogenate was centrifuged at $900 \mathrm{~g}$ for $10 \mathrm{~min}$ at $4{ }^{\circ} \mathrm{C}$. The supernatant was separated and stored at $-30^{\circ} \mathrm{C}$ until required. Total proteins were determined by the Bradford method [67].

\subsection{Lipid Peroxidation}

Fifty $\mu \mathrm{L}$ of $\mathrm{CH}_{3} \mathrm{OH}$ with $4 \%$ BHT plus phosphate buffer $\mathrm{pH} 7.4$ were added to $100 \mu \mathrm{g}$ of kidney homogenate. The mixture was shaken vigorously in a vortex for $5 \mathrm{~s}$ and then incubated in a water bath at $37^{\circ} \mathrm{C}$ for $30 \mathrm{~min} .1 .5 \mathrm{~mL}$ of $0.8 \mathrm{M}$ thiobarbituric acid were then added and the sample was incubated in a water bath at boiling temperature for $1 \mathrm{~h}$. After this time and to stop the reaction, the samples were placed on ice; $1 \mathrm{~mL} 5 \% \mathrm{KCl}$ was added to each sample as well as $4 \mathrm{~mL}$ n-butanol. Samples were shaken in a vortex for $30 \mathrm{~s}$ and centrifuged at $4000 \mathrm{rpm}$ at room temperature for $2 \mathrm{~min}$. Then the n-butanol phase was extracted, and the absorbance was measured at $532 \mathrm{~nm}$ [68].

\subsection{Evaluation of Total Antioxidant Capacity}

One hundred $\mu \mathrm{g}$ of kidney homogenate ware suspended in $1.5 \mathrm{~mL}$ of a reaction mixture prepared as followed: $300 \mathrm{mM}$ acetate buffer $\mathrm{pH} 3.6,20 \mathrm{mM}$ hexahydrate of ferric chloride, $10 \mathrm{mM}$ of 2,4,6-tris-2-pyridil-s-triazine dissolved in $40 \mathrm{mM}$ chlorhydric acid. The solutions were added in a relation of 10:1:1 $v / v$, respectively. The mixture was shaken vigorously in a vortex for $5 \mathrm{~s}$. It was then incubated at $37^{\circ} \mathrm{C}$ for $15 \mathrm{~min}$ in the dark. The absorbance was measured at $593 \mathrm{~nm}$ [59].

\subsection{Vitamin C}

One hundred $\mu \mathrm{g}$ of kidney homogenate were added to $20 \%$ trichloroacetic acid. After vigorous shaking the samples were kept in an ice bath for $5 \mathrm{~min}$ and centrifuged at $5000 \mathrm{rpm}$ for $5 \mathrm{~min} .200 \mu \mathrm{L}$ of Folin-Ciocalteu reagent $0.20 \mathrm{mM}$ were added to the supernatant. The mixture was shaken vigorously in a vortex for $5 \mathrm{~s}$ and incubated for $10 \mathrm{~min}$. The absorbance was measured at $760 \mathrm{~nm}[59]$.

\subsection{Carbonylation}

One hundred $\mu \mathrm{g}$ of kidney homogenate were added to $500 \mu \mathrm{L}$ of $\mathrm{HCl} 2.5 \mathrm{~N}$. Another sample with $500 \mu \mathrm{L}$ of 2,4-dinitrophenylhydrazine (DNPH) and incubated in the dark at room temperature for one hour, shaking with a vortex every $15 \mathrm{~min}$ was run in parallel. At the end of the incubation period, $500 \mu \mathrm{L}$ of $20 \%$ trichloroacetic acid were added, and the sample was centrifuged at $15,000 \times g$ for $5 \mathrm{~min}$. The supernatant was discarded. Two washings were performed, first removing the precipitate with a sealed capillary tube by adding $1 \mathrm{~mL}$ ethanol/ethyl acetate. It was incubated for $10 \mathrm{~min}$, and centrifuging at $15,000 \times \mathrm{g}$ for $10 \mathrm{~min}$. Finally, $1 \mathrm{~mL}$ of $6 \mathrm{M}$ guanidine hydrochloride in $20 \mathrm{mM} \mathrm{KH}_{2} \mathrm{PO}_{4} \mathrm{pH}$ 2.3 was added. The mixture was incubated again at $37^{\circ} \mathrm{C}$ for $30 \mathrm{~min}$. Absorbance was read 
in a spectrophotometer at $370 \mathrm{~nm}$, using water bi-distilled as blank and a molar absorption coefficient of $22,000 \mathrm{M}^{-1} \mathrm{~cm}^{-1}$ [59].

\subsection{GSH Concentration}

One hundred $\mu \mathrm{g}$ of kidney homogenate previously deproteinized with $20 \%$ trichloroacetic acid (vol/vol) and centrifugated to $10,000 \times g$ for $5 \mathrm{~min}$, were added to $800 \mu \mathrm{L}$ of phosphate buffer $50 \mathrm{mM}$, pH 7.3, plus $100 \mu \mathrm{L}$ of Ellman's reagent (5, 5'-dithiobis-2-nitrobenzoic acid) $1 \mathrm{M}$. The mixture was incubated at room temperature for $5 \mathrm{~min}$ and absorbance was read at $412 \mathrm{~nm}$ [59].

\subsection{3. $\mathrm{NO}_{3}{ }^{-} / \mathrm{NO}_{2}{ }^{-}$Ratio}

The $\mathrm{NO}_{3}{ }^{-}$was reduced to $\mathrm{NO}_{2}{ }^{-}$by the nitrate reductase enzyme reaction. $100 \mu \mathrm{L}$ of plasma previously deproteinized with $0.5 \mathrm{~N}, \mathrm{NaOH}$ and $10 \%, \mathrm{ZnSO}_{4}$ were mixed, and the supernatant was incubated for $30 \mathrm{~min}$ at $37^{\circ} \mathrm{C}$ in presence of nitrate reductase (5 units). At the end of the incubation period, $200 \mu \mathrm{L}$ of sulfanilamide $1 \%$ and $200 \mu \mathrm{L}$ of N-naphthylethyldiamine $0.1 \%$ were added and the total volume was adjusted to $1 \mathrm{~mL}$. The absorbance was measured at $540 \mathrm{~nm}$ [59].

\subsection{Superoxide Dismutase, Peroxidase and Catalase Activities in Native Gels}

One hundred $\mu \mathrm{g}$ of kidney homogenate were used for measurement of the activity of the SOD isoforms, peroxidase, and CAT. The determinations were performed in $10 \%$ polyacrylamide native gels. SOD and CAT isoforms were revealed according to the methods that were previously described by Pérez-Torres et al. [28]. Purified SOD from bovine erythrocytes with a specific activity of $112 \mathrm{U} / \mathrm{mg}$ of protein (Sigma-Aldrich, St. Louis, MO, USA) and purified CAT from a bovine liver having a specific activity of $60 \mathrm{U} / \mathrm{mg}$ (SigmaAldrich) were used as positive controls. The previously mentioned antioxidant enzyme activity determinations were performed according to the manufacturer's instructions. Samples were placed in a separate lane of the gel and run in parallel with the biological samples. The intensity of the signal from the controls was used as a reference to measure the enzymatic activity in the tissue samples. Therefore, the results are expressed as $U$ of activity per mg of protein. The gels were analyzed by densitometry with the Kodak Image ${ }^{\circledR}$ 3.5 [68].

For the peroxidase activity, $35 \mu \mathrm{L}$ of horseradish peroxidase was loaded to a final concentration of $178.5 \mu \mathrm{g}$ as a standard and $100 \mu \mathrm{g}$ of protein in the same conditions of the native gel were run as previously described. To observe the activity of the peroxidases, the gel was washed with distilled water three times, during $5 \mathrm{~min}$, and it was then incubated with a mixture of $0.003 \mathrm{mg} / \mathrm{mL}$ 3,3,5,5-tetramethylbenzidine dissolved in a solution of ethanol: acetic acid: water (1:1:1) with $\mathrm{H}_{2} \mathrm{O}_{2}$ for $10 \mathrm{~min}$ in the dark. In these conditions, where peroxidases are present, the gel remains transparent and 3,3,5,5-tetramethylbenzidine is oxidized showing a green coloration. The gels for peroxidase activities were analyzed by densitometry with a Kodak Image ${ }^{\circledR} 3.5$ system, and activities were calculated following the technique described above for SOD isoforms and CAT [19].

\subsection{Enzymes That Use Glutathione and/or Oxidized Glutathione}

For the GPx, GST, and GR activities, $100 \mu \mathrm{g}$ of kidney homogenate were utilized according to previously described methods [56]. The GPx activity is expressed as nmol of NADPH oxidized $/ \mathrm{min} / \mathrm{mg}$ protein, with an extinction coefficient of $6220 \mathrm{M}^{-1} \mathrm{~cm}^{-1}$ at $340 \mathrm{~nm}$ for NADPH. The GST activity is expressed as units of GS-TNB mol/min/mg protein with an extinction coefficient of $14,150 \mathrm{M}^{-1} \mathrm{~cm}^{-1}$. The GR activity is expressed as $\mu \mathrm{mol}$ of reduced GSSG/min/mg protein, with an extinction coefficient of $6220 \mathrm{M}^{-1} \mathrm{~cm}^{-1}$.

\subsection{Histopathological Analysis}

Tissue was processed for light microscopy according to standard techniques. A segment of kidney was dissected, decapsulated and washed in $0.9 \% \mathrm{NaCl}$ for $30 \mathrm{~s}$, fixed 
in $10 \%$ formalin solution for $24 \mathrm{~h}$, gradually dehydrated in ethanol, cleared in xylene, and embedded in paraffin. The kidney was cut into five-micrometer-thick slices with a microtome (Leica RM212RT, Wetzlar, Germany); the paraffin sections were stained with periodic acid-Schiff stain (PAS). Histological sections were analyzed at $400 \times$ magnification using a model 63300 light microscope (Carl Zeiss, Oberkochen, Germany), equipped with a Tucsen (9 megapixels) digital camera equipped with the TSview 7.3.1 software. The glomerular area was analyzed by densitometry using the Sigma Scan Pro 5 Image Analysis software, (Systat Software Inc., San Jose, CA, USA). The density values are expressed as pixel units.

\subsection{Statistical Analysis}

The Sigma Plot 14 program (Systat Software Inc. 2107, San Jose, CA95131 EE.UU. North First Street, Suite 360) was used to generate the graphs and to perform the statistical analyses. The data are presented as the mean \pm SE. Statistical significance was determined by one-way ANOVA test, followed by Tukey's post hoc test. Differences were considered as statistically significant when $p \leq 0.05$.

\section{Conclusions}

Treatment with a $2 \%$ HSL infusion protects renal function in a MS rat model through the natural antioxidants present in it. These compounds contribute to decrease body weight, TG, insulin, HOMA index and leptin levels. Furthermore, they favor the correct renal vascular response, which contributes to the increase in the glomerular filtration rate leading to a better $\mathrm{CCr}$, which reduces hypertension. In addition, the HSL infusion also promotes an increase in the enzymatic and non-enzymatic antioxidant systems leading to a decrease in OS and reversing the impaired renal function. Figure 7 summarizes the beneficial effect of $2 \%$ HSL infusion in the protection of renal damage in a rat model of MS.

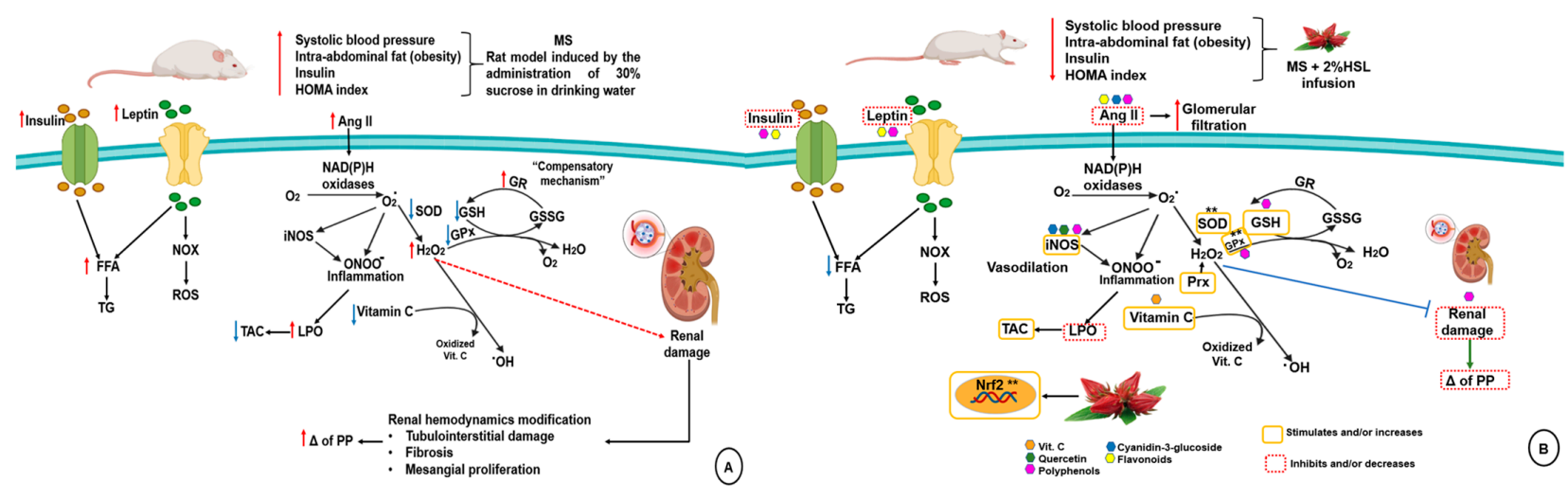

Figure 7. Panel (A) renal damage in metabolic syndrome on the alteration of the enzymatic and non-enzymatic antioxidant systems. Panel (B) Effect of 2\% HSL infusion on enzymatic and non-enzymatic antioxidant systems in kidney of the MS rats. Abbreviations: FFA = free fatty acids, $\mathbf{H}_{\mathbf{2}} \mathbf{O}_{\mathbf{2}}=$ hydrogen peroxide, $\mathbf{H S L}=$ Hibiscus sabdariffa $\mathrm{L}$., $\mathbf{G P x}=$ glutathione peroxidase, GR = glutathione reductase, GSH = glutathione, GSSG = oxidized glutathione, LPO = lipoperoxidation, MS = metabolic syndrome NOX = nicotinamide adenine dinucleotide phosphate oxidase, iNOS = inducible nitric oxide, $\mathbf{O}_{2}{ }^{-}$= superoxide anion, $\mathbf{O H}=$ hydroxyl radical, $\mathbf{O N O O}^{-}=$peroxynitrate, $\mathbf{P r x}=$ peroxidases, $\mathbf{R O S}=$ reactive oxygen species, $\mathbf{S O D}=$ superoxide dismutase, $\mathbf{T A C}=$ total antioxidant capacity, $\mathbf{T G}=$ triglycerides.

Author Contributions: F.L.R.-F. Designed the experiments; V.G.-L. Made revised and structured the manuscript; M.E.S. Made some the laboratory determination; L.M.-P. Designed and made the graphical abstract; E.D.D. Performing the blood biochemistry; E.S.-C. Performing histology description; E.R.-R. and F.J.-T. Were in charge of the care of the experimental animals; I.P.-T. Designed the study, wrote the manuscript and the statistical study. All authors have read and agreed to the published version of the manuscript. 
Funding: This research received no external funding.

Institutional Review Board Statement: The experiments with laboratory rats were approved by the Laboratory Animal Care Committee of our institution and were conducted in compliance with the Guide for the Care and Use of Laboratory Animals of NIH.

Informed Consent Statement: Not applicable.

Data Availability Statement: The datasets generated and analyzed during the current study are available from the corresponding author on reasonable request.

Acknowledgments: We thank the Postgraduate Section in the Program of Maestría y Doctorado en Ciencias de la Producción y de la Salud Animal of the UNAM for a scholarship to Félix Leao Rodríguez-Fierros. We thank Benito Chávez Rentería for histology technical support.

Conflicts of Interest: The authors declare no conflict of interest.

Sample Availability: Samples of the compounds are available from the authors.

\section{References}

1. Pérez-Torres, I.; Guarner, V.; El Hafidi, M.; Baños, G. Sex hormones, metabolic syndrome and kidney. Curr. Top. Med. Chem. 2011, 11, 1694-1705. [PubMed]

2. Nashar, K.; Egan, B.M. Relationship between chronic kidney disease and metabolic syndrome: Current perspectives. Diabetes. Metab. Syndr. Obes. 2014, 7, 421-435. [CrossRef] [PubMed]

3. Zuo, L.; Zhou, T.; Panell, B.K.; Ziegler, A.C.; Best, T.M. Biological and physiological role of reactive oxygen species-the good, the bad and the ugly. Acta Physiol. 2015, 214, 329-348. [CrossRef] [PubMed]

4. Roberts, C.K.; Sindhu, K.K. Oxidative stress and metabolic syndrome. Life Sci. 2009, 84, 705-712. [CrossRef]

5. Krata, N.; Zagozdzon, R.; Foroncewicz, B.; Mucha, K. Oxidative Stress in Kidney Diseases: The Cause of the Consequence? Arch. Immunol. Ther. Ex. 2018, 66, 211-220. [CrossRef]

6. Ighodaro, O.M.; Akinloye, O.A. First line antioxidants-superoxide dismutase (SOD), catalase (CAT) and gluthione peroxidase (GPX): Their fundamental role in the entire antioxidant defense grid. Alexandria. J. Med. 2018, 54, 287-293. [CrossRef]

7. Bretón-Romero, R.; Lamas, S. Hydrogen peroxide signaling in vascular endothelial cells. Redox. Biol. 2014, 2, 529-534. [CrossRef]

8. Sies, H. Hydrogen peroxide as a central redox signaling molecule in physiological oxidative stress: Oxidative eustress. Redox. Biol. 2017, 11, 613-619. [CrossRef]

9. Goyal, M.M.; Basak, A. Human catalase: Looking for complete identity. Protein. Cell 2010, 10, 888-897. [CrossRef]

10. Pérez-Torres, I.; Guarner-Lans, V.; Rubio-Ruiz, M.E. Reductive stress in inflammation-associated diseases and the pro-oxidant effect of antioxidant agents. Int. J. Mol. Sci. 2017, 18, 2098. [CrossRef]

11. Samsam-Shariat, S.Z.; Bolhasani, M.; Sarrafzadegan, N.; Najafi, S.; Asgary, S. Relationship between blood peroxidases activity and visfatin levels in metabolic syndrome patients. ARYA Atheroscler. 2014, 10, 218-226.

12. Raza, H. Dual localization of glutathione S-transferasa in the cytosol and mitochondria: Implications in oxidative stress, toxicity and disease. FEBS Lett. 2011, 278, 4243-4251. [CrossRef] [PubMed]

13. Sharma, M.; Gupta, S.; Singh, K.; Mehndiratta, M.; Gautam, A.; Kalra, O.P.; Shukla, R.; Gambhir, J.K. Association of glutathione-Stransferasas with patients of type 2 diabetes mellitus with and without nephronpathy. Diabetes Metab. Syndr. 2016, 10, 194-197. [CrossRef] [PubMed]

14. Rubio-Ruiz, M.E.; Guarner-Lans, V.; Cano-Martínez, A.; Díaz-Díaz, E.; Manzano-Pech, L.; Gamas-Magaña, A.; Castrejón-Tellez, V.; Tapia-Cortina, C.; Pérez-Torres, I. Resveratrol and quercetin administration improves antioxidant DEFENSES and reduces fatty liver in metabolic syndrome rats. Molecules 2019, 24, 1297. [CrossRef] [PubMed]

15. Bajic, V.P.; VanNeste, C.; Obradovic, M.; Zafirovic, S.; Radak, D.; Bajic, V.B.; Essack, M.; Isenovic, E.R. Glutathione “Redox Homeostasis" and Its Relation to Cardiovascular Disease. Oxid. Med. Cell Longev. 2019, 2019, 5028181. [CrossRef] [PubMed]

16. Pérez-Torres, I.; Ruíz-Ramírez, A.; Baños, G.; El-Hafidi, M. Hibiscus sabdariffa linnaeus (Malvaceae), curcumin and resveratrol as alternative medicinal agents against metabolic syndrome. Cardiovasc. Hematol. Agents Med. Chem. 2013, 11, 25-37. [CrossRef]

17. Wen-Chin, L.; Chau-Jong, W.; Yu-Hsin, C.; Jen-Dong, H.; Su-Ya, C.; Hong-Chen, C.; Huei-Jane, L. Polyphenols Extracts from Hibiscus sabdariffa Linnaeus Attenuate Nephropathy in experimental type 1 diabetes. J. Agric. Food Chem. 2009, 57, $2206-2210$.

18. Shun-Ting, C.; Hsin-Yi, L.; Chia-Cheng, L.; Lu-Chen, C.; Pei-Chi, C.; Yu-Chen, L.; Tin-Yun, H.; Chien-Yun, H. Exploring the effect and mechanism of Hibiscus sabdariffa on urinary tract infection and experimental renal inflammation. J. Ethnopharmacol. 2016, $194,617-625$.

19. Pérez-Torres, I.; Torres-Narváez, J.C.; Guarner-Lans, V.; Díaz-Díaz, E.; Perezpeña-Díazconti, M.; Romero-Palacios, A.; ManzanoPech, L. Myocardial protection from ischemia reperfusion damage by the antioxidant effect of Hibiscus sabdariffa linnaeus on metabolic syndrome rats. Oxid. Med. Cell Longev. 2019, 2019, 1724194. [CrossRef]

20. Ojulari, O.V.; Gi, L.S.; Nam, J.O. Beneficial effects of natural bioactive compounds from Hibiscus Sabdariffa L on obesity. Molecules 2019, 24, 210. [CrossRef] 
21. Zuñiga-Muñoz, A.M.; Guarner-Lans, V.; Díaz-Cruz, A.; Diaz-Diaz, E.; Nava-Cuellar, C.; Beltrán-Rodríguez, U.; Pérez-Torres, I. Modulation of oxidative stress in fatty liver of rat with metabolic syndrome by Hibiscus Sabdariffa. Immun. Endoc. Agen. Med. Chem. 2013, 13, 1-10.

22. Ghadge, A.A.; Khaire, A.A. Leptin as a predictive marker for metabolic syndrome. Cytokine 2019, 121, 154735. [CrossRef]

23. Diez-Echave, P.; Vezza, T.; Rodríguez-Nogales, A.; Ruiz-Malagón, A.J.; Hidalgo-García, L.; Garrido-Mesa, J.; Molina-Tijeras, J.A.; Romero, M.; Robles-Vera, I.; Pimentel-Moral, S.; et al. The prebiotic properties of Hibiscus sabdariffa extract contribute to the beneficial effects in diet-induced obesity in mice. Food Res. Int. 2020, 127, 108722. [CrossRef]

24. Hashimoto, S.; Maoka, T.; Kawata, T.; Mochizuki, T.; Koike, T.; Shigematsu, T. Roles of insulin receptor substrates (IRS) in renal function and renal hemodynamics. PLoS ONE 2020, 15, e0242332. [CrossRef]

25. Sasaki, R.; Nishimura, N.; Hoshino, H.; Isa, Y.; Kadowaki, M.; Ichi, T.; Tanaka, A.; Shin, N.; Fukuda, I.; Ashida, H.; et al. Cyanidin 3-glucoside ameliorates hyperglycemia and insulin sensitivity due to downregulation of retinol binding protein 4 expression in diabetic mice. Biochem. Pharmacol. 2007, 74, 1619-1627. [CrossRef] [PubMed]

26. Riaz, G.; Chopra, R. A review on phytochemistry and therapeutic uses of Hibiscus sabdariffa L.. Biomed. Pharmacother. 2018, 102, 575-586. [CrossRef]

27. Joven, J.; March, I.; Espinel, E.; Fernández-Arroyo, S.; Rodríguez-Gallego, E.; Aragonès, G.; Beltrán-Debon, R.; Alonso-Villaverde, C.; Rios, L.; Martin-Paredero, V.; et al. Hibiscus sabdariffa extract lowers blood pressure and improves endothelial function. Mol. Nutr. Food Res. 2014, 58, 1374-1378. [CrossRef] [PubMed]

28. Lim, Y.C.; Budin, S.B.; Othman, F.; Latip, J.; Zainalabidin, S. Roselle polyphenols exert potent negative inotropic effects via modulation of intracellular calcium regulatory channels in isolated rat heart. Cardiovasc. Toxicol. 2017, 17, 251-259. [CrossRef]

29. Lin, C.Y.; Huang, C.S.; Huang, C.Y.; Yin, M.C. Anticoagulatory, antiinflammatory, and antioxidative effects of protocat- echuic acid in diabetic mice. J. Agric. Food Chem. 2009, 57, 6661-6667. [CrossRef] [PubMed]

30. Locatelli, F.; Pozzoni, P.; Del Vecchio, L. Renal manifestations in the metabolic sydrome. J. Am. Soc. Nephrol. 2006, 17, S81-S85. [CrossRef] [PubMed]

31. Yi-Sun, Y.; Chau-Jong, W.; Chien-Ning, H.; Mu-Lin, C.; Ming-Jinn, C.; Chiung-Huei, P. Polyphenols of Hibiscus sabdariffa improved diabetic nephropathy via attenuating renal epithelial mesenchymal transition. J. Agric. Food Chem. 2013, 61, 7545-7551.

32. Ali, B.H.; Cahliková, L.; Opletal, L.; Karaca, T.; Manoj, P.; Ramkumar, A.; Al Suleimani, Y.M.; Al za'abi, M.; Nemmar, A.; Chocholousova-Havlikova, L.; et al. Effect of aqueous extract and anthocyanins of calyces of Hibiscus sabdariffa (Malvaceae) in rats with adenine-induced chronic kidney disease. J. Pharm. Pharmacol. 2017, 69, 1219-1229. [CrossRef] [PubMed]

33. Nwachukwu, D.C.; Aneke, E.I.; Nwachukwu, N.Z.; Azubike, N.; Obika, L.F. Does consumption of an aqueous extract of Hibscus sabdariffa affect renal function in subjects with mild to moderate hypertension? J. Physiol. Sci. 2016, 67, 227-234. [CrossRef] [PubMed]

34. Melchert, A.; Canuto, R.A.; Genari, V.; Salvador-Gonzalez, F.M.; Prandini de la Costa, R.R.; Guimaraes-Okamoto, P.T.C.; Amaro, J.L.; Canavese, R.S. Effect of Hibiscus sabdariffa supplementation on renal function and lipid profile in obese rats. Asian J. Anim. Vet. Adv. 2016, 11, 693-700. [CrossRef]

35. Imig, J.D.; Cook, K.A.; Inscho, W.E. Postglomerular vasoconstriction to angiotensin II and norepinephrine depends on intracellular calcium release. Gen. Phamacol. 2000, 34, 409-415. [CrossRef]

36. Correia, A.G.; Madden, A.C.; Bergtröm, G.; Evan, R.G. Effects of renal medullary and intravenous norepinephrine on renal antihypertensive function. Hypertension 2000, 35, 965-970. [CrossRef] [PubMed]

37. Rafikova, O.; Salah, E.M.; Tofovic, S.P. Renal and metabolic effects of tempol in obese ZSF1 rats-distinct role for superoxide and hydrogen peroxide in diabetic renal injury. Metabolism 2008, 57, 1434-1444. [CrossRef] [PubMed]

38. Hatoum, O.A.; Binion, D.G.; Miura, H.; Telford, G.; Otterson, M.F.; Gutterman, D.D. Role of hydrogen peroxide in ACh-induced dilation of human submucosal intestinal microvessels. Am. J. Physiol. Heart Circ. Physiol. 2005, 288, H48-H54. [CrossRef]

39. Park, S.W.; Noh, H.J.; Sung, D.J.; Kim, J.G.; Kim, J.M.; Ryu, S.Y.; Kang, K.J.; Kim, B.; Bae, Y.M.; Cho, H. Hydrogen peroxide induces vasorelaxation by enhancing 4-aminopyridine-sensitive Kv currents through S-glutathionylation. Eur. J. Physiol. 2015, 467, 285-297. [CrossRef]

40. Cseko, C.; Bagi, Z.; Koller, A. Biphasic effect of hydrogen peroxide on skeletal muscle arteriolar tone via activation of endothelial and smooth muscle signaling pathways. J. Appl. Physiol. 2004, 97, 1130-1137. [CrossRef]

41. Kanner, J. Polyphenols by generating $\mathrm{H}_{2} \mathrm{O}_{2}$, affect cell redox signaling, inhibit PTPs and activate Nrf2 axis for adaptation and cell surviving: In vitro, In vivo and human health. Antioxidants 2020, 9, 797. [CrossRef] [PubMed]

42. Erdei, N.; Bagi, Z.; Edes, I.; Kaley, G.; Koller, A. $\mathrm{H}_{2} \mathrm{O}_{2}$ increases production of constrictor prostaglandins in smooth muscle leading to enhanced arteriolar tone in type 2 diabetic mice. Am. J. Physiol. Heart Circ. Physiol. 2007, 292, H649-H656. [CrossRef]

43. Makino, A.; Skelton, M.M.; Zou, A.P.; Cowley, A.W. Increased medullary $\mathrm{H}_{2} \mathrm{O}_{2}$ leads to hypertension. Hypertnesion 2003, 42, 25-30. [CrossRef] [PubMed]

44. Ozbek, E. Induction of Oxidative Stress in Kidney. Int. J. Nephrol. 2012, 2012, 465897. [CrossRef] [PubMed]

45. Azadmanesh, J.; Borgstahl, G.E.O. A Review of the catalytic mechanism of human manganese superoxide dismutase. Antioxidants 2018, 25, 25. [CrossRef]

46. Liu, Y.; Ma, C.; Lv, L.; Li, P.; Ma, C.; He, S.; Zeng, J.; Ping, F.; Huabing, Z.; Li, W. Relationship between Decreased Serum Superoxide Dismutase Activity and Metabolic Syndrome Mediating Role of Insulin Resistance and B-Cell Dysfunction. Oxid. Med. Cell Longev. 2020, 2020, 5384909. [CrossRef] 
47. Jung, O.S.; Marklund, L.; Geiger, H.; Pedrazzini, T.; Busse, R.; Brandes, R.P. Extracellular superoxide dismutase is a major determinant of nitric oxide bioavailability: In vivo and ex vivo evidence from ecSOD-deficient mice. Cir. Res. 2003, 93, 622-629. [CrossRef]

48. Adler, S.; Huang, H. Oxidant stress in kidneys of spontaneously hypertensive rats involves both oxidase overexpression and loss of extracellular superoxide dismutase. Am. J. Physiol. Renal. Physiol. 2004, 287, F907-F913. [CrossRef]

49. Pérez-Torres, I.; Castrejón-Téllez, V.; Soto, M.E.; Rubio-Ruiz, M.E.; Manzano-Pech, L.; Guarner-Lans, V. Oxidative stress, plant natural antioxidants, and obesity. Int. J. Mol. Sci. 2021, 22, 1786. [CrossRef]

50. Soto, M.E.; Zuñiga-Muñoz, A.; Guarner-Lans, V.; Duran-Hernández, E.J.; Pérez-Torres, I. Infusion of Hibiscus sabdariffa L. Modulates oxidative stress in patients with marfan syndrome. Mediators. Inflamm. 2016, 2016, 8625203. [CrossRef]

51. Prakash, P.A.; Yogeswaran, U.; Chen, S.M. A review on direct electrochemistry of catalase for electrochemical sensors. Sensors 2009, 9, 1821-1844. [CrossRef] [PubMed]

52. Mirochnitchenko, O.; Weisbrot-Lefkowitz, M.; Reuhl, K.; Chen, L.; Yang, C.; Inouye, M. Acetaminophen toxicity. Opposite effects of two forms of glutathione peroxidase. J. Biol. Chem. 1999, 274, 10349-10355. [CrossRef] [PubMed]

53. Whitin, J.C.; Bhamre, S.; Tham, D.M.; Harvey, J.C. Extracellular glutathione peroxidase is secreted basolaterally by cells of the human renal proximal tubule. J. Physiol. Renal. Physiol. 2002, 283, F20-F28. [CrossRef]

54. Shu, W.; Moustaid-Moussa, N.; Chen, L.; Mo, H.; Shastri, A.; Su, R.; Bapat, P.; Kwun, I.; Shen, C.L. Novel insights of dietary polyphenols and obesity. J. Nutr. Biochem. 2014, 25, 1-18.

55. Curtis, J.M.; Grimsrud, P.A.; Wright, W.S.; Xu, X.; Foncea, R.E.; Graham, D.W.; Brestoff, J.R.; Wiczer, B.M.; Ilkayeva, O.; Cianflone, K.; et al. Downregulation of adipose glutathione S-transferase A4 leads to increased protein carbonylation, oxidative stress, and mito-chondrial dysfunction. Diabetes 2010, 59, 1132-1142. [CrossRef] [PubMed]

56. Zúñiga-Muñoz, A.M.; Pérez-Torres, I.; Guarner-Lans, V.; Núñez-Garrido, E.; Velázquez-Espejel, R.; Huesca-Gómez, C.; GamboaÁvila, R.; Soto, M.E. Glutathione system participation in thoracic aneurysms from patients with Marfan syndrome. Vasa 2017, 46, 177-186. [CrossRef]

57. Rybka, J.; Kupczyk, D.; Kędziora-Kornatowska, K.; Motyl, J.; Czuczejko, J.; Szewczyk-Golec, K.; Kozakiewicz, M.; Pawluk, H.; Carvalho, L.A.; Kędziora, J. Glutathione- related antioxidant defense system in elderly patients treated for hypertension. Cardiovasc. Toxicol. 2011, 11, 1-9. [CrossRef]

58. Vávrová, L.; Kodydková, J.; Zeman, M.; Dusejovska, M.; Macasek, J.; Stankova, B.; Tvrzicka, E.; Zak, A. Altered activities of antioxidant enzymes in patients with metabolic syndrome. Obes. Facts 2013, 6, 39-47. [CrossRef] [PubMed]

59. Aisa-Alvarez, A.; Soto, M.E.; Guarner-Lans, V.; Camarena-Alejo, G.; Franco-Granillo, J.; Martínez-Rodríguez, E.A.; Gamboa-Ávila, R.; Manzano-Pech, L.; Pérez-Torres, I. Usefulness of antioxidants as adjuvant therapy for septic shock: A randomized clinical trial. Medicina (Kaunas) 2020, 56, 619. [CrossRef]

60. Pérez-Torres, I.; Zúñiga-Muñoz, A.; Beltrán-Rodríguez, U.; Díaz-Díaz, E.; Martínez-Memije, R.; Guarner-Lans, V. Modification of the liver fatty acids by Hibiscus sabdariffa Linnaeus (Malvaceae) infusion, its possible effect on vascular reactivity in a metabolic syndrome model. Clin. Exp. Hypertens. 2014, 36, 123-131. [CrossRef]

61. Jagota, S.K.; Dani, H.M. A new colorimetric technique for the estimation of vitamin C using Folin phenol reagent. Anal. Biochem. 1982, 127, 178-182. [CrossRef]

62. Jia, Z.S.; Tang, M.C.; Wu, J.M. The determination of flavonoid contents in mulberry and their scavenging effects on superoxide radicals. Food Chem. 1999, 64, 555-559.

63. Lee, J.; Durst, R.W.; Wrolstad, R.E. Determination of total monomeric anthocyanin pigment content of fruit juices, beverages, natural colorants, and wines by the $\mathrm{pH}$ differential method: Collaborative Study. J. AOAC Int. 2005, 88, 1269-1278. [CrossRef] [PubMed]

64. BenGershôm, E. Screening for albuminuria: A case for estimation of albumin in urine. Clin. Chem. 1975, 21, 1795-1798. [CrossRef]

65. Jaffe, M. Ueber den niederschlag welchen pikrinsäure in normalen harn erzeugt und über eine neue reaction des kreatinins. $Z$. Physiol. Chem. 1886, 10, 391-400. (In Polish)

66. Pérez-Torres, I.; El Hafidi, M.; Pavón, N.; Infante, O.; Avila-Casado, M.C.; Baños, G. Effect of gonadectomy on the metabolism of arachidonic acid in isolated kidney of a rat model of metabolic syndrome. Metabolism 2010, 59, 414-423. [CrossRef]

67. Bradford, M.M. A rapid and sensitive method for the quantitation of microgram quantities of protein utilizing the principle of protein-dye binding. Anal. Biochem. 1976, 72, 248-254. [CrossRef]

68. Pérez-Torres, I.; Roque, P.; El Hafidi, M.; Diaz-Diaz, E.; Baños, G. Association of renal damage and oxidative stress in a rat model of metabolic syndrome. Influence of gender. Free Rad. Res. 2009, 43, 761-771. [CrossRef] 